\title{
Shareholder Litigation and the Information Content of Management Voluntary Disclosure
}

\author{
A Dissertation \\ SUBMITTED TO THE FACULTY OF \\ UNIVERSITY OF MINNESOTA \\ BY
}

Yuanyuan Ma

\section{IN PARTIAL FULFILLMENT OF THE REQUIREMENTS FOR THE DEGREE OF DOCTOR OF PHILOSOPHY}

Advisers: Frank Gigler and Chandra Kanodia

April, 2016 


\section{Acknowledgements}

I am deeply indebted to my advisors, Frank Gigler and Chandra Kanodia, for their guidance and encouragement on this project. I am especially grateful to Frank Gigler for his continuous support throughout my $\mathrm{PhD}$ study. I also thank Tim Baldenius, Dain Donelson, Kai Du, Prasart Jongjaroenkamol, Volker Laux, Tong Lu, Xiaojing Meng, Mark Nelson, Paul Newman, Anywhere Seiko, and Gaoqing Zhang for their helpful comments and suggestions.

I also want to thank my husband, Wenbin Huang, for his understanding and support ever since I decided to start my $\mathrm{PhD}$ study in accounting. Without his firm support, I wouldn't have achieved so much in the six special years of my life. 


\begin{abstract}
In this paper I study the information content of managers' voluntary disclosures in a shareholder litigation environment. I model the litigation mechanism in which the legal liability is based on the actual damages shareholders incur from buying a stock at an inflated price. I find that the optimal disclosure strategy in equilibrium does not fully reveal a manager's information and has the manager making what are essentially range disclosures. In addition, more favorable news is more informative than less favorable news when legal liability is high, and the converse is true when legal liability is low. I also find that increasing the severity of legal liability does not necessarily induce more precise disclosures. Initially, the disclosure precision is enhanced by increases in legal liability, but beyond a point, increases in legal liability reduce the disclosure precision.
\end{abstract}




\section{Table of Contents}

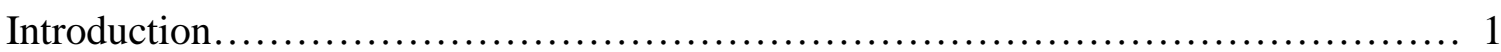

Related Literature .......................................................... 5

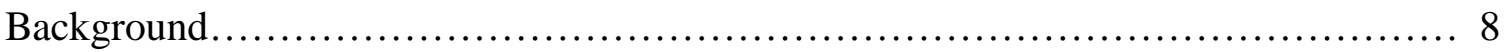

The Model............................................................. 11

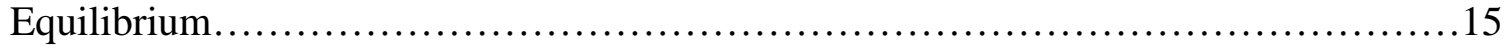

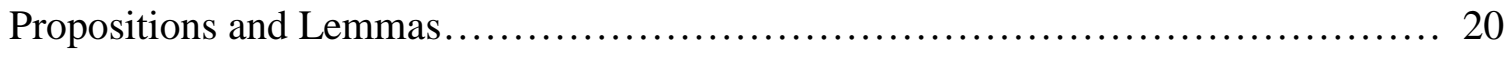

Conclusion................................................................ 22

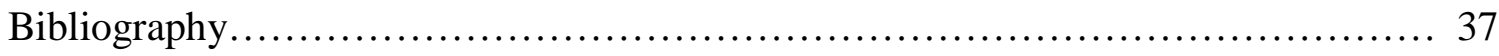

Appendix.................................................................. 40 


\section{Introduction}

Shareholder litigation enforcing Rule 10b-5 of the Securities Exchange Act of 1934 is an important mechanism that disciplines managers' voluntary disclosures. Under this rule, shareholders can initiate a lawsuit against a firm and the manager for providing misleading information that inflates the stock price and results in shareholder damages. The threat of these shareholder lawsuits presumably disciplines managers' disclosures $e x$ ante. A prominent feature of the shareholder litigation mechanism is that the legal liability is based on the damages that shareholders suffer from buying a stock at an inflated price. This feature implies that the potential penalty that a manager needs to assess while making a disclosure is based on the stock price, which is the market reaction to her disclosure, rather than her disclosure per se. I study how effective this "indirect" penalty disciplines managers' voluntary disclosures and how changing the severity of the legal liability can enhance or hinder the information content of voluntary disclosures.

Statistics in Nera (2015) show that (1) about $60 \%$ of the 4,435 securities class action suits filed during years 1996-2014 are settled out of court, (2) the dismissal rate remains relatively constant over the years at around 40\%, and (3) only 21 cases go to trial. Thus, the legal liability imposed by shareholder litigation is indeed the settlement amount. When the lawsuits are categorized according to the amount of investor losses, the ratio of the settlement amount to investor losses is not much different across the different groups, varying from $0.7 \%$ to $8.8 \%$, except for the lowest group. ${ }^{1}$ This suggests that the settlement amount in shareholder litigation is roughly a fraction of shareholder damages. I model the shareholder litigation mechanism based on these empirical facts to study its role in disciplining managers' disclosure strategies when they have an incentive to inflate the stock price by misreporting.

I find that, in equilibrium, a manager does not fully reveal her private information through disclosure. Instead, the manager only discloses a general range of her information. In addition, the information content of good news differs from that of bad news, and the difference depends on the severity of the legal liability. In particular, when the legal liability is low, bad news disclosures have more information content than good

\footnotetext{
${ }^{1}$ The investor loss for the lowest group is lower than 1 million, and the ratio for that group is $17.9 \%$. These lawsuits are typically regarded as frivolous lawsuits by researchers.
} 
news disclosures; in contrast, when the legal liability is high, good news disclosures have more information content than bad news disclosures. Interestingly, the severity of the legal liability does not enhance the information content of disclosures monotonically. Instead, increases in the legal liability, up to a certain level, enhance the information content of disclosures. However, beyond that level, increases in the legal liability reduce the information content of disclosures.

Two features of my litigation model distinguish this paper from prior studies in the literature on voluntary disclosure and litigation. The first one is that managers' private information is unverifiable, even during a lawsuit. Thus, legal liability cannot be based on true information; consequently, a litigation mechanism that implements truthful disclosures does not exist, ${ }^{2}$ and it cannot be assumed that disclosures are always truthful. Given that managers can potentially lie, it is essential to study the role of the litigation mechanism in deterring managers from lying. By contrast, in prior literature, legal liability more or less relies on the verifiability of the truth (Trueman, 1997; Evans and Sridhar, 2002; Laux and Stocken, 2012; Dye, 2014; and Dye, 2015). If the truth were verifiable, however, it would be puzzling why truthful disclosures are not implemented all the time since the first-best litigation mechanism would exist in that case. It is this puzzle that motivates this study and drives the non-verification assumption in this model.

The second feature of my litigation model is that legal liability is, in essence, based on the inference that the market makes from the manager's disclosure. This is because legal liability is based on shareholder damages, which are essentially stock price declines, and the stock price following a disclosure is the market's valuation conditional on the information it infers from the disclosure. This inference-based penalty is much different from the disclosure-based penalty ${ }^{3}$ modeled in many studies in the voluntary disclosure literature (e.g., Fischer and Verrecchia 2000; and Beyer and Guttman, 2011).

\footnotetext{
${ }^{2}$ When information is verifiable, truth telling can be implemented in a "first best" litigation mechanism which inflicts an infinite penalty on the manager when the disclosure is verified to be different from the truth. The verifiability assumption is implicitly made in classic voluntary disclosure theories (Grossman, 1981; Milgrom, 1981; Jovanovic, 1982; Verrecchia, 1983; Dye, 1985; Jung and Kwon, 1988). However, when information is unverifiable, the "first best" mechanism cannot be implemented.

${ }^{3}$ The penalty is assumed to be quadratic in the disclosure error, which is the difference between the disclosed value and the realized value of the variable of interest, e.g., the difference between the forecast of earnings and the actual earnings.
} 
These studies show that when the penalty is based on disclosures per se, a manager would take a biased disclosure strategy. In equilibrium, the manager suffers a penalty for the bias, while the stock price is not distorted by the biased disclosure because the market can perfectly infer the true information of the manager from her disclosure. In contrast, an inference-based penalty implies that when the market can perfectly infer the true information of the manager and the stock price is not distorted by the disclosure, the penalty would be zero since investors do not suffer damages.

When the penalty is based on market inference from the disclosure, the trade-off that the manager faces involves a circular problem. Her disclosure strategy depends on the expectation of the penalty, which is based on the inference that the market makes from her disclosure, but the market inference reflectively depends on her disclosure strategy. I am able to solve this circular problem by adopting the approach of Crawford and Sobel (1982). It may seem that communication is costly in this disclosure setting and the approach of a cheap talk model should not apply. However, it is the endogeneity rather than the absence of the communication cost that distinguishes a cheap talk model. In addition, the cost to disclosure in my model endogenously arises from the inference that the market makes from the disclosure. In this way, my setting is completely compatible with the model in Crawford and Sobel where the information disclosed imposes an implicit cost on the sender through the equilibrium action taken by the receiver in response to the sender's communication.

I find that in equilibrium, managers' typical disclosure strategy is to reveal a range in which their information lies so their private information is not fully revealed by their disclosures. Consequently, the stock price is not always true to the information and is sometimes inflated. Such an inflation in the stock price rationalizes shareholders' damages: a large inflation is more likely to be followed by a large stock price decline that could trigger a lawsuit, which, in turn, imposes a penalty on the manager.

Another insight brought by the model is that the effect of legal liability on the precision of managers' disclosures is non-monotone. The precision of managers' disclosures increases with the legal liability only when it is below a certain level; beyond that level, the precision is reduced by further increases in the legal liability. The intuition is that because legal liability is incurred when the stock is over-priced, it works to partly 
offset the manager's incentive to opportunistically inflate the stock price. When the legal liability is not too high, increasing it decreases the manager's desire to inflate the stock price and the disclosure becomes more informative in equilibrium. However, when the legal liability is too high, it imposes excessive litigation risk on the manager and she would actually want to deflate the firm's stock price. Thus, the higher the legal liability, the more the manager would want to understate the value of the firm and the less precise information the manager would provide. This result is again substantially different from that derived in previous studies where the penalty is based on disclosure per se. The result in Guttman, Kadan and Kandel (2006) suggests that when the penalty is quadratic in the disclosure error, an increase in the penalty always decreases the bias in managers' disclosures, and thereby increases the disclosure precision monotonically.

The model also yields an interesting result on the comparative information content of good news and bad news. When the legal liability is low, bad news disclosures have more information content than good news disclosures; when the legal liability is high, good news has more information content than bad news. This is because when the legal liability is low, managers want to over-report in order to inflate the stock price, and thus more favorable disclosures do not have as much information content as less favorable disclosures. However, when the legal liability is high, more favorable disclosures are more informative than less favorable disclosures since managers want to under-report so as to deflate the stock price. 


\section{Related Literature}

This paper contributes primarily to the literature on litigation and disclosures by modeling the endogenous legal liability that is based on actual shareholder damages and by studying the role of the litigation mechanism in deterring managers from misrepresenting information. Trueman (1997), Dye (2014), and Dye (2015) focus on the role of the litigation mechanism in preventing managers from omitting material information, and assume disclosures are always truthful. In their litigation models, the fact that the manager had material information can be detected ex post with a positive probability, and the true information is perfectly verified upon detection. Evans and Sridhar (2002), Laux and Stocken (2012), and Nan and Wen (2015) are closer to this paper in that they also consider the role of litigation in disciplining the credibility of disclosures. The former two studies assume that the true information is perfectly revealed ex post, and that litigation inflicts a fixed penalty on the manager if the disclosure is untruthful. As a result, the only impediment to enforcing full and honest disclosure is the limited liability faced by management. My assumption is different in that I assume managers' information is unverifiable, so legal liability is not based on the truth but on the actual damages that shareholders suffer. Nan and Wen (2015) also assume that managers' information is unverifiable, but their focus is whether the litigation mechanism is good for social welfare since the penalty could be imposed mistakenly due to the nonverifiability of the manager's true information. Caskey (2014) and Spindler (2011) also assume that legal liability is based on stock price declines. Caskey (2014) focuses on the pricing effect of damage-based legal liability rather than the effect of legal liability on disclosures. In his model, legal liability affects the manager's payoff through a pricing effect because the manager's compensation is based on the stock price. In my model, legal liability serves as a potential cost to disclosure and it affects the manager's payoff because of the two-way interaction between the disclosure and the legal liability through the stock price. In Spindler (2011), legal liability is imposed exogenously: a lawsuit occurs whenever there is a stock price decline, and the probability of imposing legal liability on the firm is fixed given a lawsuit. Consequently, one of results in his paper is that if the probability of enforcing legal liability following any stock price decline is not equal to one, the litigation mechanism cannot deter the manager from misrepresentation 
in her disclosure. In contrast, in my model, lawsuits are endogenous since filing a lawsuit is a rational decision made by shareholders. As a result, the litigation mechanism can discipline credible disclosures even when the probability of enforcing the legal liability is less than one.

In addition to the literature on litigation, this paper also contributes to the literature on voluntary disclosures of non-verifiable information. Newman and Sansing (1993) and Gigler (1994) also model an endogenous cost of disclosures. In their studies, the endogenous cost is a proprietary cost, i.e., an optimistic disclosure induces a choice of the competitor that is unfavorable to the manager who makes the disclosure. Newman and Sansing (1993) show that the existence of a competitor in the audience of the manager's disclosure makes her intentionally introduce noise into her disclosure and essentially prompts her to make a range disclosure. Gigler (1994) establishes that an endogenous proprietary cost can make unverifiable voluntary disclosures credible. The resulting equilibrium disclosures are also in the form of range disclosures. The equilibrium disclosures in this paper take the same form as these two papers, but it provides a new rationale for the prevalent observations of range forecasts. Fischer and Stocken (2001) establish that the quality of disclosures does not increase monotonically with the quality of information possessed by the informed party. In their study, equilibrium disclosures also take the range form, and the quality of disclosures is exactly the same as the precision of disclosures in this paper. Compared to their finding, I find that the quality of disclosures does not increase monotonically with the severity of the legal liability.

Besides the proprietary cost addressed by Newman and Sansing (1993) and Gigler (1994), Stocken (2000) shows that a manager's concern about her reputation can also establish the credibility of unverifiable disclosures in repeated game setting. Evans and Sridhar (2002) show that the litigation mechanism can make disclosures more credible by adding a more disciplining force in addition to the proprietary cost in the product market. In this paper, I show that the shareholder litigation mechanism, modeled in a different way, can discipline credible disclosures without forces from the product market.

Fischer and Verrecchia (2000), Beyer (2009), Beyer and Guttman (2011), and Einhorn and $\mathrm{Ziv}$ (2012) show that when there is an exogenous convex cost to the 
informed party that is based on the difference between the disclosure and the realization of the variable of interest, the equilibrium strategy is a monotone biased strategy. The informed party's information is fully revealed in equilibrium. In this paper, I show that if the cost to the manager is endogenously based on the market inference of the disclosures, managers' information can be fully revealed only in a knife-edge case, and that a fully revealing equilibrium almost never exists. 


\section{Background}

Rule 10b-5 of the Securities Exchange Act of 1934 makes it unlawful to "make any untrue statement of a material fact or to omit to state a material fact necessary in order to make the statements made... not misleading." 4 To state the cause of a lawsuit under Rule 10b-5, a plaintiff must allege and prove six elements: (1) that the defendant made a material misrepresentation or omission, (2) that the defendant acted with a scienter or wrongful state of mind, (3) that the plaintiff actually purchased or sold securities, (4) that the plaintiff relied on the material misrepresentation, (5) that the plaintiff suffered an economic loss as a result, and (6) that the material misrepresentation actually caused the loss (Fletcher III, 1989; Kaufman and Wunderlich, 2010).

Among the six elements, the third one is the easiest to prove. Francis, Philbrick, and Schipper (1994) discuss four of the other elements, materiality, reliance, damages, and causality, as follows: "Causality and materiality might be demonstrated together by showing that a specific information release is uniquely associated with a statistically significant movement in share price," and sometimes a significant price reaction is not even "necessary to establish the materiality of the alleged misleading disclosures." As for reliance, "under the fraud on the market theory... plaintiffs can say they relied on the integrity of the market price instead of showing that they relied on a specific disclosure that contained bad or missing information." Thus, reliance can be easily established based on the "fraud on the market" theory. Materiality and causality can also be easily established as long as a manager's disclosure is sufficiently informative and moves the stock price significantly. Therefore, the remaining two elements, scienter and damages, are the elements of major concern in this paper.

One way that plaintiffs can allege scienter is to plead that the defendant has the motive and opportunity to misrepresent information and inflate the stock price. Thus, if the manager's personal benefit (e.g., compensation) is linked to the stock price, the plaintiffs can meet the scienter standard by showing the manager's compensation as evidence at least in some circuits. ${ }^{5}$ In my model, since I am interested in the role of

\footnotetext{
4 CFR $\$ 240.10 b-5$.

${ }^{5}$ After the Private Securities Litigation Reform Act of 1995 (PSLRA), different circuits developed diverse pleading standards in their attempts to apply the scienter standard. For example, the Second Circuit held
} 
litigation in disciplining managers' disclosures when they have the incentive to manipulate and face the risk of being sued (if managers do not have incentives to manipulate, there would be no role of the litigation mechanism), I only focus on the setting where the manager's compensation is related to the stock price. Therefore, scienter is an element that could potentially be established by shareholders in a lawsuit.

The damages element requires that plaintiffs demonstrate that they suffered economic loss between the disclosure date and the date when "corrective" information is revealed. When there is a large stock price decline between the two dates, shareholders suffer actual damages. They can establish the damages element in a lawsuit by demonstrating that even after excluding the part of the price change that is attributable to the market and industry factors during the period, there is still a stock price decline between the two dates. I do not model the market and industry factors in my paper, and therefore the presence of a stock price decline between the two dates is sufficient to establish the damages element.

In practice, even before plaintiffs can successfully establish all of the six elements, almost all of the lawsuits are settled before reaching the trial stage. This is because the trial process is extremely strenuous and usually takes a long time before a judgment is reached, so managers are easily distracted and have to deal with the negative impact of the lawsuit on various aspects of the firm's business. In addition, Choi (2004) points out that "many companies have liability insurance policies for their directors and officers, many of which will not pay if the directors or officers are found culpable at trial for violating the securities laws. Rather than face this prospect (even if unlikely), directors and officers will often settle, relying on the directors and officers (D\&O) liability insurers to pay most, if not all, of the settlement award." From the viewpoint of the plaintiffs, settling with the firm at least secures a partial recovery of their damages in contrast to going through the long discovery process and trial which may finally lead to an unfavorable judgment. As a consequence, almost all Rule 10b-5 lawsuits end up with

that "plaintiffs can plead a strong inference of fraudulent intent by including sufficient allegations that the defendants received concrete, personal benefits from the alleged fraud," while the Ninth Circuit held that "plaintiffs had to plead, 'at a minimum, particular facts giving rise to a strong inference of deliberate or conscious recklessness.” See Choi (2004) for details. 
settlements if they are not dismissed. Therefore, the effective legal liability in the shareholder litigation mechanism is, in fact, the settlement amount. 


\section{The Model}

A risk neutral manager who has private information about the firm's value makes a decision on how to disclose her information at date 1 . Firm value $\tilde{y}$ at date 2 is uniformly distributed on $[x-\varepsilon, x+\varepsilon]$. The manager privately knows $x$ at date 1 , and makes disclosure $m$ to the market. For interpretation purposes, the manager's private information $x$ is sometimes referred to as the fundamental value of the firm or the type of the manager. The market has a prior belief that $x$ is uniformly distributed on the interval $[\underline{x}, \bar{x}]$. After observing the manager's disclosure, the market values the firm based on the information contained in disclosure $m$, and the valuation is stock price $p$ at date 1 . At date 2 , the realization of the firm value, $y$, is revealed to the market, and the stock price at date 2 is equal to $y .^{6}$

The manager has an incentive to boost the stock price through the disclosure because her compensation is increasing in the stock price. For simplicity, I assume that the manager's compensation is $\alpha p$. Although the manager can misrepresent her information in her disclosure to boost the stock price and her compensation, she is concerned about a potential lawsuit. In particular, if the stock price tumbles from date 1 to date 2 , shareholders suffer damages, $p-y$, and they may want to sue the manager. If they sue the manager at date 2 , they expect to receive a settlement amount from the firm, and the lawyers charge them a fixed fee $c^{7}$. Skinner (1997) documents that the settlement amount is usually only a small fraction of the total shareholder damages, the median of the settlement amount as a fraction of the estimated shareholder damages is $1.9 \%$, and the quartiles are $0.8 \%$ and 3.7\%, respectively. Donelson, Hopkins and Yust (2015) document that estimated damages are a significant determinant of settlement amounts. Based on

\footnotetext{
${ }^{6} y$ is the stock price that is used to calculate the damages that shareholders suffer between the disclosure date and the date on which "corrective" information is revealed. Although the actual stock price at date 2, $p_{2}$, may be lower than $y$ due to shareholders' anticipation of a lawsuit, $p_{2}$ is not used as the basis to calculate shareholder damages because the price drop from $y$ to $p_{2}$ is not caused by the manager's disclosure, and is therefore not treated as shareholder damages.

7 The results will not change qualitatively if the lawyers charge a commission in proportion to the settlement amount in addition to the fixed amount $c$. Let $c$ be the effort cost that lawyers expect to incur in filing a lawsuit. Lawyers would decide to file a lawsuit for shareholders only if the expected commission exceeds $c$. For simplicity, I assume that the lawyer market is completely competitive and the commission is fixed at $c$.
} 
these observations, I assume that the settlement amount is linear in shareholder damages, i.e., the settlement amount is $\beta(p-y)$.

Although the dismissal rate in reality is about $40 \%$ so the probability that shareholders can get a settlement amount is not one, I do not introduce the probability of a lawsuit being dismissed in my model for the sake of simplicity - the results do not change qualitatively as long as the probability of a filed lawsuit being dismissed is common knowledge to shareholders and the manager. Even if the probability of dismissal is not constant but decreasing in the amount of shareholder damages, the results will still not change qualitatively.

Klausner and Hegland (2010) find that in 94\% of their shareholder litigation sample, the settlement amount is paid either by the companies or by their D\&O insurers. However, even if the manager does not pay any portion of the settlement amount, a settlement inevitably has a negative impact on her. For example, the manager may incur a reputation cost due to a settlement of a lawsuit. The higher the settlement amount, the higher reputation loss the manager could suffer. In this paper, I assume that in a shareholder lawsuit the manager incurs a personal cost, $\gamma \beta(p-y)$, which is increasing in the settlement amount.

The equilibrium considered in this paper is Bayesian Nash equilibrium, where the manager adopts a mixed strategy on the support of the market's prior belief, $[\underline{x}, \bar{x}]$. The market does not take the manager's disclosure at face value; rather, it infers the manager's information from the disclosure. In equilibrium, shareholders sue the manager when the expected net payoff of suing the manager is positive; the manager takes shareholders' suing strategy into consideration, and chooses a disclosure strategy that maximizes her expected utility, and the inference that the market makes from a disclosure is consistent with the manager's disclosure strategy.

I analyze the problem using backward induction. At date 2, when $y$ is revealed to the market, if the stock price drops from the date 1 price so that the shareholders suffer a loss, they make a decision on whether to file a lawsuit. If they sue the manager, their expected payoff is the expected settlement amount minus the fees paid to the lawyers, i.e., $\beta(p-y)-c$; while if they do not sue, their payoff is zero. Denote the shareholders' 
litigation strategy as $S(p, y)$, which takes value 1 if they decide to sue the manager, and 0 if they decide not to sue. Then, their decision is to choose $S(p, y)=1$ when $\beta(p-y)-$ $c>0$, i.e., when $y<p-\frac{c}{\beta}$; and $S(p, y)=0$ otherwise. ${ }^{8}$ Thus, the shareholders' litigation strategy is a threshold strategy: $S(p, y)=\left\{\begin{array}{c}1, \text { if } y<p-\frac{c}{\beta} \\ 0, \text { otherwise }\end{array}\right.$, that is, the shareholders decide to sue the manager when the new information at date 2 is sufficiently unfavorable so that the price drops below the previously guided price by more than $\frac{c}{\beta}$.

Denote the personal cost to the manager induced by a potential lawsuit as $l(p, y)$, then given the litigation strategy of the shareholders,

$$
l(p, y)=\left\{\begin{array}{c}
\gamma \beta(p-y), \text { if } y<p-\frac{c}{\beta} \\
0, \text { otherwise }
\end{array}\right.
$$

At date 1 when the manager makes a disclosure, the realization of firm value $y$ is unknown to the manager, but date 2 firm value $\tilde{y}$ is uniformly distributed around the manager's private information $x$; therefore, the manager can form an expectation of the potential cost based on her information $x$. Denote the manager's expected cost as $L(p, x)=E_{y}[l(p, y) \mid x]$. For ease of interpretation, I refer to $L(p, x)$ as the manager's expected litigation cost.

The manager's decision is to choose a disclosure strategy, $q(m \mid x)$, that maximizes her net payoff $\alpha p(m)-L(p(m), x)$, i.e., her compensation minus the expected litigation cost, for any given $x$. The stock price that affects the manager's payoff, $p(m)$, is the market's expectation of the firm value based on the message disclosed by the manager, ${ }^{9}$ and is therefore a function of disclosure $m$. The manager's

\footnotetext{
${ }^{8}$ Donelson and Hopkins (2016) find that the probability of litigation and the amount of settlements both double when earnings disclosures occur during a large market decline even though market-wide events are legally irrelevant. This evidence suggests that shareholders do base their suing decisions on the expectation of the payoff from a lawsuit since they have little information to judge the scienter of the manager at the time they make the suing decision.

${ }^{9}$ I assume that the turnover of stocks at any time is one. Then, although stock buyers at date 1 expect to get a settlement award if there is a settlement later, there will be a reduction in the firm value of the same amount due to the settlement payment. The two effects cancel out and date 1 stock price is simply equal to the expectation of firm value conditional on the disclosure. Even if a firm pays the settlement amount through the D\&O insurance, since insurance is purchased out of the equity of the firm, as long as the insurer charges the firm a higher insurance premium following a settlement and the extra insurance cost is equal to the settlement amount, the reduction in the firm value due to a settlement will be equal to the
} 
disclosure strategy $q(m \mid x)$ is a mixed strategy on the support of the prior belief of the market $[\underline{x}, \bar{x}]$, i.e., $m \in[\underline{x}, \bar{x}]$, and $q(m \mid x)$ specifies the probability that a particular $m$ is disclosed for a given $x$. Since $m$ is not restricted to be equal to $x$, the manager is allowed to lie in this model. The equilibrium disclosure strategy is strategy $q(m \mid x)$ that is sustained in the equilibrium defined below.

settlement award that shareholders expect to get, and shareholders do not include the expected settlement amount into the pricing of the firm at date 1. 


\section{Equilibrium}

An equilibrium consists of a litigation strategy of shareholders, $S(p, y)$, a pricing function, $p(m)$, and the disclosure strategy of the manager, $q(m \mid x)$, such that:

$$
S(p, y)=\left\{\begin{array}{l}
1, \text { if } y<p-\frac{c}{\beta} \\
0, \text { otherwise }
\end{array}\right.
$$

(ii) for each $m \in[\underline{x}, \bar{x}], \quad p(m)=E(y \mid m)=\int_{\underline{x}}^{\bar{x}} E(y \mid x) p(x \mid m) d x$, where

$$
p(x \mid m)=\frac{q(m \mid x)}{\int_{\underline{x}}^{\bar{x}} q(m \mid x) d x}
$$

(iii) for each $x \in[\underline{x}, \bar{x}], \int_{\underline{x}}^{\bar{x}} q(m \mid x) d m=1$, if a particular $m$ is in the support of $q(\cdot \mid x)$, then $m$ solves $\max _{m \in[x, \bar{x}]} \alpha p(m)-L(p(m), x)$.

Given that date 2 firm value $\tilde{y}$ is uniformly distributed on the interval $[x-\varepsilon, x+$ $\varepsilon]$, if $x-\varepsilon+\frac{c}{\beta} \leq p \leq x+\varepsilon+\frac{c}{\beta}$, then $x-\varepsilon \leq p-\frac{c}{\beta} \leq x+\varepsilon$, i.e., the threshold of the shareholders' litigation strategy $S(p, y)$ is within the interval in which $y$ could possibly lie. Then, given $l(p, y)$ as in equation $(1), L(p, x)=E_{y}[l(p, y) \mid x]=\int_{x-\varepsilon}^{p-\frac{c}{\beta}} \gamma \beta(p-y)$. $\frac{1}{2 \varepsilon} d y=\frac{\gamma \beta}{4 \varepsilon}\left[(p-x+\varepsilon)^{2}-\left(\frac{c}{\beta}\right)^{2}\right]$. If $p<x-\varepsilon+\frac{c}{\beta}$, date 2 firm value $y$ can never fall below the threshold of the shareholders' litigation strategy, $p-\frac{c}{\beta}$, i.e., the probability that shareholders will sue is zero; hence, the manager's expected litigation cost is zero. If $p>x+\varepsilon+\frac{c}{\beta}$, the price guided by the disclosure is so high that date 2 firm value $y$ is, for sure, lower than the threshold of a lawsuit, and the probability of a lawsuit is one. Therefore, $L(p, x)=\gamma \beta(p-x)$.

Let $\underline{p}(x)=x-\varepsilon+\frac{c}{\beta}$, and $\bar{p}(x)=x+\varepsilon+\frac{c}{\beta}$, then the manager's expected litigation cost function is in the following form:

$$
L(p, x)=\left\{\begin{array}{cc}
0, & \text { if } p<\underline{p}(x) \\
\frac{\gamma \beta}{4 \varepsilon}\left[(p-x+\varepsilon)^{2}-\left(\frac{c}{\beta}\right)^{2}\right], & \text { if } \underline{p}(x) \leq p \leq \bar{p}(x) \\
\gamma \beta(p-x), & \text { if } p>\bar{p}(x)
\end{array}\right.
$$


The key feature of this cost, which is associated with a disclosure, is that it is not a function of the disclosure per se; rather, it is a function of the stock price, which is based on the inference that the market makes from the disclosure. Thus, as long as the inference that the market makes from the disclosure is correct so that the stock price is not inflated, the manager does not incur a legal liability, even if a disclosure is not identical to the manager's information. ${ }^{10}$ This feature distinguishes this model from previous disclosure models that assume the cost associated with a disclosure is based on the disclosure per se (Fischer and Verrecchia, 2000; Beyer, 2009; Beyer and Guttman, 2011; and Einhorn and Ziv, 2012). Specifically, those models assume that the disclosurerelated cost is a quadratic function of the disclosure error, which is the difference between the disclosure and the realization of the variable of interest. Under this assumption, the manager bears a positive expected cost as long as the disclosure is not identical to her information, even if the market is not misled by the disclosure and the stock price is true to the information.

The expected litigation cost function has the following three properties. First, the expected litigation cost to the manager is (weakly) increasing in the difference between the stock price guided by the manager's disclosure and her private information on the firm's fundamentals.

Second, the probability of a shareholder lawsuit breaks from zero to non-zero at price $\underline{p}(x)$. If the stock price guided by the manager's disclosure is lower than this level, the manager does not have any risk of being sued. However, when the stock price is above this level, the manager faces a positive probability of being sued.

The breaking price level $p(x)$ is determined by the fundamental value of the firm, $x$, as well as three other factors: the uncertainty in the firm value, $\varepsilon$, the transaction cost in the litigation system, $c$, and the severity of the legal liability, $\beta$. If the firm value is

\footnotetext{
${ }^{10}$ In my model, when $p=x, L(p, x)=\frac{\gamma \beta}{4 \varepsilon}\left[\varepsilon^{2}-\left(\frac{c}{\beta}\right)^{2}\right] \neq 0$. There are two reasons for this. The first reason is that frivolous lawsuits, which are lawsuits after a stock price decline that is caused simply by the uncertainty in the firm value, could occur due to the non-verifiability of the manager's information $x$. In other words, the manager could be sued even if her disclosure is not misleading, because there is uncertainty in the firm value and the manager's information is unverifiable. The second reason is that the transaction cost $c$ in the litigation mechanism prevents a lawsuit from occurring whenever the manager's disclosure misleads the market.
} 
highly uncertain, the transaction cost in the litigation mechanism is low and the legal liability is severe, the probability of the manager being sued could be positive even when she guides the stock price to be lower than the fundamental value of the firm. When uncertainty about the firm value is low, the transaction cost in the litigation mechanism is high, and the legal liability is not severe, then the probability of the manager being sued could be zero even when she guides the stock price to be higher than the fundamental value.

Third, the marginal cost of manipulating the stock price is well ordered across managers with different fundamental values. In particular, at any given price level, a manager with a higher fundamental value has a lower marginal cost of manipulating the stock price than a manager with a lower fundamental value, i.e., $L_{p x}(p, x) \leq 0$ for any $p$ and $x$.

Denote the manager's expected utility function as $U(p, x)=\alpha p-L(p, x)$, then,

$$
U(p, x)=\left\{\begin{array}{cc}
\alpha p, & \text { if } p<\underline{p}(x) \\
\alpha p-\frac{\gamma \beta}{4 \varepsilon}\left[(p-x+\varepsilon)^{2}-\left(\frac{c}{\beta}\right)^{2}\right], & \text { if } \underline{p}(x) \leq p \leq \bar{p}(x) \\
(\alpha-\gamma \beta) p+\gamma \beta x, & \text { if } p>\bar{p}(x)
\end{array}\right.
$$

Note that when the stock price is guided by the disclosure to be higher than $\bar{p}(x)$, i.e., when a future lawsuit is to occur with probability one, the expected utility is linear in the stock price with the coefficient $\alpha-\gamma \beta$. If $\alpha>\gamma \beta$, then the manager would want to boost the stock price infinitely. To rule out this unrealistic case, I assume $\gamma \beta>\alpha$, i.e., the penalty coefficient is higher than the benefit coefficient. Thus, once the stock price is guided to the high litigation risk range, the expected utility of the manager is decreasing in the stock price.

Because the expected litigation cost increases disproportionately with a boosted price, while the benefit of a higher stock price is linear in the price, the expected utility function exhibits a hump shape. It first increases with the stock price when the price is low relative to the fundamentals, but as the price rises above a certain level, the marginal expected cost outweighs the marginal benefit of a higher stock price and the expected utility becomes decreasing in the stock price. In particular, the expected utility function has a single peak, denoting $p^{*}(x) \cdot p^{*}(x)=x+\varepsilon\left(\frac{2 \alpha}{\gamma \beta}-1\right)$ if $\alpha>\frac{\gamma c}{2 \varepsilon}$, and $p^{*}(x)=\underline{p}(x)$ 
if $\alpha \leq \frac{\gamma c}{2 \varepsilon}$, where $\frac{\gamma c}{2 \varepsilon}$ is the marginal litigation cost of manipulating the stock price at the highest no-risk level $\underline{p}(x)$.

To see this, it is useful to lay out the marginal utility of manipulating the stock price below:

$$
U_{p}(p, x)=\left\{\begin{array}{cc}
\alpha, & \text { if } p<\underline{p}(x) \\
\alpha-\frac{\gamma \beta}{2 \varepsilon}(p-x+\varepsilon), & \text { if } \underline{p}(x) \leq p \leq \bar{p}(x) \\
\alpha-\gamma \beta, & \text { if } p>\bar{p}(x)
\end{array}\right.
$$

At $\underline{p}(x)=x-\varepsilon+\frac{c}{\beta}$, i.e., the highest price that induces zero probability of lawsuits, the marginal litigation cost of manipulating the stock price is equal to $\frac{\gamma \beta}{2 \varepsilon} \cdot \frac{c}{\beta}=$ $\frac{\gamma c}{2 \varepsilon}$. Thus $\alpha \leq \frac{\gamma c}{2 \varepsilon}$ corresponds to the case where the marginal litigation cost of manipulating the stock price is so high compared to the incentive of doing so, that even a remote probability of being sued makes the manager's utility worse off. In contrast, $\alpha>\frac{\gamma c}{2 \varepsilon}$ represents the case where the marginal litigation cost is not too high so that a higher stock price with a small probability of being sued is better for the manager than a lower stock price with no risk of being sued. The second case is obviously more general and reasonable than the first one; hence, I assume $\alpha>\frac{\gamma c}{2 \varepsilon}$ throughout the paper. Thus, the single peak of the expected utility function is $p^{*}(x)=x+\varepsilon\left(\frac{2 \alpha}{\gamma \beta}-1\right)$.

A special feature of the expected utility function of the manager is that her choice variable, disclosure $m$, does not show up directly. The variable that determines the manager's utility is the stock price, which is determined by the market rather than chosen by the manager. Hence, the manager's utility is not under her direct control; rather, she can only influence the market with her disclosure. This special feature of the expected utility function implies that the market has a significant impact on the information communication between the manager and the market. In particular, the market is always willing to price a firm at its fundamental value. If the manager's disclosure strategy makes it possible for the market to infer her true information (the fundamental value) $x$, then the market would price the firm at value $x$. Thus, when the manager has an incentive 
to guide the stock price away from the fundamental value, i.e., when $p^{*}(x) \neq x$, she is not willing to fully reveal her information in equilibrium. 
Proposition 1. No fully revealing disclosure strategy exists in equilibrium if $\alpha \neq \frac{\gamma \beta}{2}$.

Proof: $\alpha \neq \frac{\gamma \beta}{2}$ implies that $p^{*}(x) \neq x$. Suppose there is a fully revealing equilibrium where the manager's strategy is a one-to-one mapping $m(x)$.

Then, in the "equilibrium," it must be true that $p(m(x))=x$, i.e., the stock price is equal to the manager's type, because the market must be able to infer the manager's true type and then price the firm at the fundamental value. The utility of the manager in this "equilibrium" is then $U(p(m(x)), x)=U(x, x)$. Since $U(p, x)$ has a single peak $p^{*}(x)$ and $p^{*}(x) \neq x$, we know that $U(x, x)<U\left(p^{*}(x), x\right)$. Given the pricing function $p(m(x))=x$, the manager has an incentive to deviate from her disclosure $m(x)$ to disclosure $m^{\prime}=m\left(p^{*}(x)\right)$ so that $p\left(m^{\prime}\right)=p\left(m\left(p^{*}(x)\right)\right)=p^{*}(x)$. Hence, $m(x)$ cannot be an equilibrium strategy. That is, there cannot be any fully revealing equilibrium when $p^{*}(x) \neq x$.

Q.E.D.

Note that when $\alpha=\frac{\gamma \beta}{2}$, i.e., when $p^{*}(x)=x$, managers find it in their best interest to tell the truth in the disclosures, a fully revealing equilibrium exists. However, this is clearly a knife-edge case among all possible combinations of the parameters. Except for this knife-edge case, managers' most preferred stock price is never equal to the fundamental value of the firm, i.e., $p^{*}(x) \neq x$. The lemmas and propositions in this paper are, therefore, focused on these cases. Proposition 1 shows that a disclosure strategy that maps one-to-one from managers' private information to the disclosures cannot be an equilibrium strategy.

The intuition is as follows. Under a one-to-one mapping strategy, the market can perfectly infer the fundamental value of a firm, $x$, from a type $x$ manager's disclosure, then the market price would be equal to the fundamental value, i.e., $p=x$. However, since $p^{*}(x) \neq x$, the manager's utility is not maximized when $p=x$, hence a type $x$ manager has an incentive to make a different disclosure to induce the market to price the firm at $p^{*}(x)$ so that her utility is maximized. Therefore, a one-to-one mapping strategy cannot be sustained in equilibrium. 
The non-existence of a fully revealing disclosure strategy in this model contrasts distinctly from the existence of a monotone biased disclosure strategy in the aforementioned studies (Fischer and Verrecchia, 2000; Beyer, 2009; Beyer and Guttman 2011; and Einhorn and Ziv 2012). While managers' private information is fully revealed in equilibrium when the disclosure cost is based on the disclosure per se, it is not completely revealed in equilibrium when the disclosure cost is based on the information content of the disclosure.

Although the manager is not willing to reveal her information completely, she is willing to communicate some information to the market, because she has the desire to differentiate herself from a manager with a lower type and induce a higher stock price. This fact is quantified by Lemma 1, which shows a sorting property of managers' preferences over the stock price. According to this property, if a manager of type $x^{0}$ is indifferent between two stock prices, $p_{1}$ and $p_{2}$ where $p_{1}<p_{2}$, then all managers of higher types than $x^{0}$ would strictly prefer $p_{2}$ to any price lower than or equal to $p_{1}$, and all managers of lower types than $x^{0}$ would strictly prefer $p_{1}$ to any price higher than or equal to $p_{2}$. The intuition is that a manager with a higher fundamental value prefers to induce a higher stock price than one with a lower fundamental value, because the latter faces a higher expected litigation cost than the former if they were to induce the same stock price.

Lemma 1 (Sorting Property). If there exist $x^{0}, p_{1}$, and $p_{2}$, with $p_{1}<p_{2}$, such that $U\left(p_{1}, x^{0}\right)=U\left(p_{2}, x^{0}\right)$, then $U\left(p_{1}, x\right)>U(p, x)$ for $p \geq p_{2}$ and all $x<x^{0}$, and $U(p, x)<U\left(p_{2}, x\right)$ for $p \leq p_{1}$ and all $x>x^{0}$.

Proof: Differentiate $U_{p}(p, x)$ in (4) with respect to $x$, we have

$$
U_{p x}(p, x)= \begin{cases}0, & \text { if } p<\underline{p}(x) \\ \frac{\gamma \beta}{2 \varepsilon}, \text { if } \underline{p}(x) \leq p \leq \bar{p}(x) \\ 0, & \text { if } p>\bar{p}(x)\end{cases}
$$


Hence, $U_{p x}(p, x) \geq 0$ for any $p$ and $x,{ }^{11}$ and the strict inequality holds when $p \in(\underline{p}(x), \bar{p}(x))$. Since $p^{*}\left(x^{0}\right)=x^{0}+\varepsilon\left(\frac{2 \alpha}{\gamma \beta}-1\right) \in\left(\underline{p}\left(x^{0}\right), \bar{p}\left(x^{0}\right)\right)$, we have $U_{p x}\left(p^{*}\left(x^{0}\right), x^{0}\right)>0$. By continuity of $U_{p x}(p, x)$, there exists a neighborhood of $\left(x^{0}, p^{*}\left(x^{0}\right)\right), \Delta_{\left(x^{0}, p^{*}\left(x^{0}\right)\right)}=\left(x^{0}-\delta_{x}, x^{0}+\delta_{x}\right) \times\left(p^{*}\left(x^{0}\right)-\delta_{p}, p^{*}\left(x^{0}\right)+\delta_{p}\right)$, such that $U_{p x}(p, x)>0$ for any $(p, x) \in \Delta_{\left(x^{0}, p^{*}\left(x^{0}\right)\right)}$.

Given that $U\left(p_{1}, x^{0}\right)=U\left(p_{2}, x^{0}\right)$, and that $U\left(p, x^{0}\right)$ has a single peak at $p^{*}\left(x^{0}\right)$, we know that $p_{1}<p^{*}\left(x^{0}\right)<p_{2}$. Hence, for any $x>x^{0},\left(\left(p_{1}, p_{2}\right) \times\left(x^{0}, x\right)\right) \cap$ $\Delta_{\left(x^{0}, p^{*}\left(x^{0}\right)\right)} \neq \emptyset$; and for any $x<x^{0},\left(\left(p_{1}, p_{2}\right) \times\left(x, x^{0}\right)\right) \cap \Delta_{\left(x^{0}, p^{*}\left(x^{0}\right)\right)} \neq \emptyset$. This means that there must be a region in $\left(\left(p_{1}, p_{2}\right) \times\left(x, x^{0}\right)\right)$ where $U_{p x}(p, x)$ is strictly positive. Note that for $(p, x) \notin \Delta_{\left(x^{0}, p^{*}\left(x^{0}\right)\right)}, U_{p x}(p, x) \geq 0$. Therefore, we have

For all $x>x^{0}$,

$$
U\left(p_{2}, x\right)-U\left(p_{1}, x\right)=U\left(p_{2}, x\right)-U\left(p_{1}, x\right)-\left[U\left(p_{2}, x^{0}\right)-U\left(p_{1}, x^{0}\right)\right]=
$$

$\int_{x^{0}}^{x} \int_{p_{1}}^{p_{2}} U_{p x}(p, x) d p d x>0$.

Thus, $U\left(p_{2}, x\right)>U\left(p_{1}, x\right)$ for all $x>x^{0}$.

Note that $p^{*}(x)$ is increasing in $x$, hence $p^{*}(x)>p^{*}\left(x^{0}\right)$ for all $x>x^{0}$. Then $p_{1}<p^{*}\left(x^{0}\right)<p_{2}$ implies that $p^{*}(x)>p_{1}$ for all $x>x^{0}$. Given that $p^{*}(x)$ is the single peak, we know that $U(p, x)$ is increasing in $p$ when $p<p^{*}(x)$; hence, $U(p, x)<$ $U\left(p_{1}, x\right)$ for $p<p_{1}$ and all $x>x^{0}$.

Therefore, we have $U\left(p_{2}, x\right)>U(p, x)$ for $p \leq p_{1}$ and all $x>x^{0}$.

For all $x<x^{0}$,

$U\left(p_{2}, x\right)-U\left(p_{1}, x\right)=U\left(p_{2}, x\right)-U\left(p_{1}, x\right)-\left[U\left(p_{2}, x^{0}\right)-U\left(p_{1}, x^{0}\right)\right]=$ $-\int_{x}^{x^{0}} \int_{p_{1}}^{p_{2}} U_{p x}(p, x) d p d x<0$.

Thus, $U\left(p_{1}, x\right)>U\left(p_{2}, x\right)$ for all $x<x^{0}$.

\footnotetext{
${ }^{11} U(p, x)$ is not differentiable with respect to $p$ at $p=p(x)$ and $p=\bar{p}(x)$, and therefore, $U_{p x}(p, x)$ does not exist at these two points. However, the limits of $\bar{U}_{p x}(p, x)$ exist at these two points. Specifically, $\lim _{p \rightarrow \underline{p}(x)^{-}} U_{p x}(p, x)=0 \quad, \quad \lim _{p \rightarrow \bar{p}(x)^{+}} U_{p x}(p, x)>0 \quad, \quad \lim _{p \rightarrow \underline{p}(x)^{-}} U_{p x}(p, x)>0 \quad, \quad$ and $\lim _{p \rightarrow \bar{p}(x)^{+}} U_{p x}(p, x)=0$.
} 
Again, because $p^{*}(x)$ is increasing in $x, p^{*}(x)<p^{*}\left(x^{0}\right)$ for all $x<x^{0}$. Then $p_{1}<p^{*}\left(x^{0}\right)<p_{2}$ implies that $p^{*}(x)<p_{2}$ for all $x<x^{0}$. Given that $p^{*}(x)$ is the single peak, we know that $U(p, x)$ is decreasing in $p$ when $p>p^{*}(x)$; hence, $U(p, x)<$ $U\left(p_{2}, x\right)$ for $p>p_{2}$ and all $x<x^{0}$.

Therefore, we have $U\left(p_{1}, x\right)>U(p, x)$ for $p \geq p_{2}$ and all $x<x^{0}$.

\section{Q.E.D.}

Lemma 1 shows that managers' preferences over the stock price are well ordered across their types. The higher a manager's type, the higher her most preferred stock price is. Given the results in Proposition 1 and Lemma 1, I can adopt the approach developed in Crawford and Sobel (1982) to derive the equilibrium in this model. Crawford and Sobel (1982) develop the so-called "cheap talk" model to study a costless communication game between an informed party and an uninformed party, where the former's payoff hinges on the latter's action. They show that when the interests of the two parties are misaligned, the equilibrium signaling takes a partitioning form. It may seem inappropriate to apply the approach of a "cheap talk" model to a litigation setting where communication is potentially costly. However, as discussed in Crawford and Sobel (1982), what distinguishes their "cheap talk" model from a Spencian signaling model is the endogeneity of the communication cost to the informed party. In my model, the disclosure cost to the manager endogenously arises from the inference that the market makes from the disclosure. Therefore, it is indeed completely compatible to the "cheap talk" model. The major difference in this paper is that the market as the uninformed party does not take action to maximize its utility, as is the case in Crawford and Sobel (1982). Instead, the market prices the firm based on the inference it makes from the manager's disclosure. It turns out that the equilibrium strategy in this setting takes the same partitioning form as in the "cheap talk" model.

In the lemmas and propositions that follow, I first discuss the properties of an informative equilibrium, where at least two different prices are sustained. The conditions where an informative equilibrium does not exist are derived later. Lemma 2 shows that any prices too close to each other cannot be sustained in equilibrium. 
Lemma 2. Let $P$ be the set of prices that is induced in an informative equilibrium. If $\alpha \neq \frac{\gamma \beta}{2}$, then $P$ is finite.

Proof: Let $p_{1}$ and $p_{2}$ be two elements of $P$ where $p_{1}<p_{2}$. There must exist two types $x_{1}$ and $x_{2}$, such that $U\left(p_{1}, x_{1}\right) \geq U\left(p_{2}, x_{1}\right)$, and $U\left(p_{2}, x_{2}\right) \geq U\left(p_{1}, x_{2}\right)$.

Rewriting the two inequalities, we have

$U\left(p_{1}, x_{1}\right)-U\left(p_{2}, x_{1}\right) \geq 0$, and $U\left(p_{1}, x_{2}\right)-U\left(p_{2}, x_{2}\right) \leq 0$.

The intermediate value theorem then implies that there exists a $x^{0} \in\left[x_{1}, x_{2}\right]$ such that $U\left(p_{1}, x^{0}\right)-U\left(p_{2}, x^{0}\right)=0$, i.e., $U\left(p_{1}, x^{0}\right)=U\left(p_{2}, x^{0}\right){ }^{12}$

Given that $p^{*}\left(x^{0}\right)$ is the single peak of $U\left(p, x^{0}\right)$, we have

$p_{1}<p^{*}\left(x^{0}\right)<p_{2}$.

By Lemma 1, we know that

$U\left(p_{1}, x\right)>U\left(p_{2}, x\right)$ for all $x<x^{0}$, and $U\left(p_{2}, x\right)>U\left(p_{1}, x\right)$ for all $x>x^{0}$.

This implies that no types higher than $x^{0}$ would like to induce price $p_{1}$, and no types lower than $x^{0}$ would like to induce price $p_{2}$. Thus, if some type $x$ makes a disclosure that induces price $p_{1}$, it must be true that $x \leq x^{0}$; and if some type $x$ makes a disclosure that induces price $p_{2}$, then $x \geq x^{0}$. Let $X\left(p_{1}\right)$ be the set of type $x$ 's whose disclosure induces stock price $p_{1}$, and $X\left(p_{2}\right)$ be the set of type $x$ 's whose disclosure induces stock price $p_{2}$, then we have $p_{1}=E\left(y \mid x \in X\left(p_{1}\right)\right) \leq x^{0}$, and $p_{2}=E(y \mid x \in$ $\left.X\left(p_{2}\right)\right) \geq x^{0}$. That is,

$p_{1} \leq x^{0} \leq p_{2}$

Let $\delta=\varepsilon\left|\frac{2 \alpha}{\gamma \beta}-1\right|$, then $\delta>0$, and

$\left|p^{*}\left(x^{0}\right)-x^{0}\right| \geq \delta$.

Inequalities (6), (7), and (8) then imply that $p_{2}-p_{1}>\delta$.

Since for any $p \in P, p=E(y \mid x \in A)$, where $A$ is a subset of $[\underline{x}, \bar{x}]$ that contains all types whose disclosure induces the stock price $p$, we know that $p_{2}-p_{1} \leq \bar{x}-\underline{x}$. Thus, the number of $p$ 's in $P$ cannot be more than $\frac{\bar{x}-\underline{x}}{\delta}$. Hence, $P$ must be finite. Q.E.D.

12 By Lemma 1, it can be shown that $x_{1} \leq x_{2}$. 
Lemma 2 suggests that when managers have an incentive to misguide the stock price, the rational expectation of the market restricts managers' ability to misguide the stock price, i.e., managers cannot mislead the market to price their firms at any level they want. In particular, only a finite number of stock prices can be sustained in equilibrium. Lemma 3 shows that given a finite number of equilibrium stock prices, managers' preferences among the prices essentially partition them into a set of pools. Specifically, managers whose types are on a particular sub-interval on $[\underline{x}, \bar{x}]$ prefer a particular stock price to any other equilibrium prices. Thus, the finite number of stock prices corresponds to a partition of the support of types, $[\underline{x}, \bar{x}]$. Each sub-interval in the partition represents a pool of managers whose most preferred stock price among the finite number of stock prices is the same, and therefore, they would like to pool together and induce the same stock price.

Lemma 3. Assume $\alpha \neq \frac{\gamma \beta}{2}$. Let $P=\left\{p_{1}, p_{2}, \ldots, p_{n}\right\}$ be the set of prices that are induced in equilibrium, where $p_{1}<p_{2}<\cdots<p_{n}$. Let $x_{0}=\underline{x}$, and $x_{n}=\bar{x}$. There exist $n-1$ values $x_{1}<x_{2}<\cdots<x_{n-1}$ on $[\underline{x}, \bar{x}]$, such that any type in the interval $\left[x_{i-1}, x_{i}\right]$ prefers $p_{i}$ to all other prices in $P$ for $i=1,2, \cdots, n$.

Proof: For any $1 \leq i<n-1$, given that $p_{i}$ 's are equilibrium stock prices, by the proof of Lemma 2, $\exists x_{i}, x_{i+1} \in[\underline{x}, \bar{x}]$ such that $U\left(p_{i}, x_{i}\right)=U\left(p_{i+1}, x_{i}\right)$ and $U\left(p_{i+1}, x_{i+1}\right)=$ $U\left(p_{i+2}, x_{i+1}\right)$.

By Lemma 1, we know that

$U\left(p_{i+1}, x\right)>U(p, x)$ for all $x>x_{i}$ and $p \leq p_{i}$; and

$U\left(p_{i+1}, x\right)>U(p, x)$ for all $x<x_{i+1}$ and $p \geq p_{i+2}$

(9) and (10) imply that for any $x_{i}<x<x_{i+1}, p_{i+1}$ is strictly preferred to any other stock price in $P$.

By the proof of Lemma 2, we know that $p_{i}<p^{*}\left(x_{i}\right)<p_{i+1}$, and $p_{i+1}<$ $p^{*}\left(x_{i+1}\right)<p_{i+2}$, hence

$$
\begin{aligned}
& U\left(p_{i+1}, x_{i}\right)>U\left(p, x_{i}\right) \text { for all } p<p_{i}, \text { and } U\left(p_{i+1}, x_{i}\right)=U\left(p_{i}, x_{i}\right) \\
& U\left(p_{i+1}, x_{i+1}\right)>U\left(p, x_{i+1}\right) \text { for all } p>p_{i+2}, \text { and } U\left(p_{i+1}, x_{i+1}\right)=U\left(p_{i+2}, x_{i+1}\right)
\end{aligned}
$$


Conditions (10) and (11) imply that type $x_{i}$ is indifferent between $p_{i}$ and $p_{i+1}$, and strictly prefers these two stock prices to any other prices in $P$. Conditions (9) and (12) imply that type $x_{i+1}$ is indifferent between $p_{i+1}$ and $p_{i+2}$, and strictly prefers these two stock prices to any other price in $P$.

Applying the same argument to all the equilibrium stock prices, we can obtain all of the $x_{i}$ 's that divide $[\underline{x}, \bar{x}]$ into $n$ intervals. Any type on the interval $\left[x_{i-1}, x_{i}\right]$ prefers $p_{i}$ to all other prices in $P$ for $i=1,2, \cdots, n$.

Q.E.D.

The way managers can pool together and induce the same stock price is to make "common disclosures" that have the same information content. Lemma 3 does not specify the relationship between the equilibrium stock prices and the firm values in the "common disclosure" pools induced by the prices. In equilibrium, the stock price for a "common disclosure" pool must be a rational expectation of the firm values in the pool. Proposition 2 characterizes an equilibrium with a partition of $n$ sub-intervals (and $n$ stock prices). For ease of interpretation, I refer to the number of intervals in an equilibrium partition as the size of the equilibrium hereafter.

Proposition 2. If $\alpha \neq \frac{\gamma \beta}{2}$, then all equilibria are partition equilibria. An equilibrium of size $n$ is characterized as follows:

$S(p, y)=\left\{\begin{array}{c}1, \text { if } y<p-\frac{c}{\beta} \\ 0, \text { otherwise }\end{array}\right.$

$q(m \mid x)$ is uniform on $\left[x_{i}, x_{i+1}\right]$ if $x \in\left[x_{i}, x_{i+1}\right]$;

$p(m)=\frac{x_{i}+x_{i+1}}{2}$ if $m \in\left[x_{i}, x_{i+1}\right]$;

where $x_{i}$ 's are determined by equation (14) and boundary conditions (15) as follows:

$\alpha \cdot \frac{x_{i-1}+x_{i}}{2}-L\left(\frac{x_{i-1}+x_{i}}{2}, x_{i}\right)=\alpha \cdot \frac{x_{i}+x_{i+1}}{2}-L\left(\frac{x_{i}+x_{i+1}}{2}, x_{i}\right), i=0,1,2, \ldots, n-1$.

$x_{0}=\underline{x}, x_{n}=\bar{x}$

where $L(p, x)$ is shown in equation (2).

Proof: The shareholders' litigation strategy is discussed earlier, and is omitted here. 
Given that the manager's strategy is to randomize the disclosure on $\left[x_{i}, x_{i+1}\right]$ if $x \in\left[x_{i}, x_{i+1}\right]$, and that the market's prior belief is that $x$ is uniformly distributed on $[\underline{x}, \bar{x}]$, when the market observes a disclosure $m \in\left[x_{i}, x_{i+1}\right]$, it can infer that $x$ is uniformly distributed on $\left[x_{i}, x_{i+1}\right]$; therefore, the stock price is given by $p=$ $E\left(y \mid x \sim U\left[x_{i}, x_{i+1}\right]\right)=\int_{x_{i}}^{x_{i+1}} x \cdot \frac{1}{x_{i+1}-x_{i}} d x=\frac{x_{i}+x_{i+1}}{2}$.

Given this pricing rule by the market, consider the set of prices $\left\{p_{1}, p_{2}, \cdots p_{n}\right\}$, where $p_{i}=\frac{x_{i}+x_{i+1}}{2}$. Since $x_{i-1}, x_{i}, x_{i+1}$, and $x_{i+2}$ satisfy (14), we know that type $x_{i}$ is indifferent between $p_{i-1}$ and $p_{i}$, and type $x_{i+1}$ is indifferent between $p_{i}$ and $p_{i+1}$. By the proof of Lemma 3, we know that all types on intervals $\left[x_{i}, x_{i+1}\right]$ prefer $p_{i}$ to all other prices $p_{j}, j \neq i$. Therefore, they do not want to deviate from randomizing disclosure $m \in\left[x_{i}, x_{i+1}\right]$, which induces the price $p_{i}$, to any other disclosure $m^{\prime} \in[\underline{x}, \bar{x}] \backslash\left[x_{i}, x_{i+1}\right]$ that induces other prices $p_{j} \neq p_{i}$. Suppose the off-equilibrium belief is that $x=\underline{x}$ when the manager is silent, then all types on $\left[x_{i}, x_{i+1}\right]$ prefer randomizing disclosure $m$ on $\left[x_{i}, x_{i+1}\right]$ for all $i=1,2, \ldots, n$.

Therefore, the triple $\{S(p, y), q(m \mid x), p(m)\}$ characterized in the proposition is an equilibrium.

\section{Q.E.D.}

The equilibrium disclosure strategy of a manager is essentially the same as that in Crawford and Sobel (1982), Newman and Sansing (1993), and Gigler (1994), i.e., the manager partitions the entire range of the firm's fundamental value in the market's prior belief into sub-intervals and randomizes her disclosure on the sub-interval in which the firm's fundamental value lies. Given that the market can figure out the partition in equilibrium, the information content of the disclosure is that the firm's fundamental value is in a particular sub-interval of the support of the market's prior belief.

Since the stock price of a firm is ultimately based on the information content of a disclosure rather than the disclosure per se, many strategies can be sustained as equilibrium disclosure strategies, as long as they communicate the same information content to the market as the above randomization strategy does. One such strategy is to disclose the exact sub-interval in the equilibrium partition that contains the manager's 
type. Since it is straightforward and intuitive, I refer to this interval disclosure strategy as the equilibrium strategy in the rest of the paper.

The equilibrium interval disclosure strategy closely resembles the range forecasts that managers provide for earnings forecasts. Newman and Sansing (1993) and Gigler (1994) indicate that when the manager is concerned about the effect of her disclosure on the competitor's decision, she may want to disclose relatively vague information. This model provides another rationale for the prevalence of range forecasts, i.e., when the manager faces potential legal liability that is based on the information content of her disclosure, she is willing to reduce the information content to some extent by providing range forecasts.

With such disclosure strategies, managers of all possible types essentially form a finite number of pools. Each pool of managers makes the same disclosure to communicate the same relatively vague information to the market. Upon observing a disclosure, the market prices the firm at the average fundamental value of the firms in the pool. The equilibrium partitioning points for the pools are determined such that each manager prefers the stock price for her pool to the price for any other pool. Essentially, inducing a higher price brings more litigation cost than compensation, and inducing a lower price reduces the compensation more than the litigation cost.

Since the market prices each firm at the average fundamental value of all the firms in its pool, the stock price for each firm is not "accurate" - in each of the pools, half of the firms have a stock price below their fundamental values, and the other half have a stock price above their fundamental values. The "undervalued" managers face a lower risk of being sued, but at the same time, their compensation is compromised by the deflated stock price. The "overvalued" managers benefit from higher compensation brought by the inflated stock price, but at the same time, they must face a higher likelihood of being sued.

Ultimately, two factors contribute to an actual lawsuit. The first one is the inherent uncertainty of firm values. If the uncertainty $(\varepsilon)$ is high and the realization of the firm value $(y)$ turns out to be much lower than expected so that there is a large stock price decline, shareholders will sue the manager. The second one is the overvaluation of 
some firms. It is the existence of overvaluation in equilibrium that rationalizes shareholders' claims for damages. If the stock price were always true to the manager's information, as is the case in a fully revealing equilibrium, then all lawsuits would be frivolous lawsuits.

In summary, under the discipline of the litigation mechanism in which the legal liability is based on actual shareholder damages, managers' disclosures are credible and informative, but also imprecise. The disclosures are credible in the sense that the disclosed intervals always contain managers' true information. They are informative since the intervals are smaller than the support of the prior belief of the market. They are also imprecise - the precise information of managers cannot be inferred from the intervals.

Proposition 2 characterizes an equilibrium of size $n$ if there exists such an equilibrium, but it does not address whether and when there exists such an equilibrium. Lemma 4 explores the property of the solution sequences of equation (14) that determines the partitioning points in equilibrium, and then based on the property in Lemma 4, Proposition 3 shows that there is a maximum size of equilibrium for a given setting characterized by $\{\alpha, \beta, \gamma, \varepsilon, c\}$.

Lemma 4. If $\alpha>\frac{\gamma \beta}{2}$, let $x=\left\{x_{0}, x_{1}, \ldots, x_{j}, \ldots\right\}$ be a sequence satisfying equation (14) for $i=1,2, \cdots, j, \cdots$ with $x_{0}=\underline{x} \leq x_{1}$, then $\frac{d x_{i}}{d x_{1}}>1$ for all $i>1$; if $\alpha<\frac{\gamma \beta}{2}$, let $x^{\prime}=$ $\left\{x_{0}^{\prime}, x_{1}^{\prime}, \ldots, x_{j}^{\prime}, \ldots\right\}$ be a sequence satisfying equation (14) for $i=1,2, \cdots, j, \cdots$ with $x_{0}^{\prime}=\bar{x} \geq x_{1}^{\prime}$, then $\frac{d x_{i}^{\prime}}{d x_{1}^{\prime}}>1$ for all $i>1$.

Proof: See the Appendix.

When the compensation incentive weighs more than the litigation concern, i.e., when $\alpha>\frac{\gamma \beta}{2}$, the manager has a net incentive to inflate the stock price, i.e., $p^{*}(x)>x$. In this case, the way to find a solution sequence is to fix $x_{0}$ at $\underline{x}$, and solve for all partitioning points $x_{i}$ 's as a function of $x_{1}$ from equation (14), i.e., choosing a different $x_{1}$ leads to different solution sequences. If a sequence has an ending element that 
coincides with $\bar{x}$, it should be one equilibrium partition. When the litigation concern weighs more than the compensation incentive, i.e., when $\alpha<\frac{\gamma \beta}{2}$, the manager has a net incentive to deflate the stock price, i.e., $p^{*}(x)<x$. In this case, the way to find a solution sequence is to fix $x_{0}$ at $\bar{x}$, and also solve for all partitioning points $x_{i}$ 's as a function of $x_{1}$ from equation (14). If a sequence has an ending element that coincides with $\underline{x}$, it should be one equilibrium partition.

Lemma 4 indicates that the length of each interval in the equilibrium partition is increasing in the length of the first interval. Using this monotone pattern in the lengths of the intervals, by changing $x_{1}$ on $[\underline{x}, \bar{x}]$, we can find all the equilibrium partitions in a given context defined by $\{\alpha, \beta, \gamma, \varepsilon, c\}$.

Proposition 3. For a given combination of $\{\alpha, \beta, \gamma, \varepsilon, c\}$, there is a maximum size, $N$, of equilibrium. For each $1 \leq n \leq N$, there is one and only one equilibrium of size $n .^{13}$

Proof: See the Appendix.

Proposition 3 shows that for any given context characterized by the compensation coefficient $\alpha$, the legal liability parameter $\beta$, the manager's cost coefficient $\gamma$, the uncertainty in firm value $\varepsilon$, and the legal $\operatorname{cost} c$, there is a maximum size of equilibrium, and there can be multiple equilibria of different sizes. Since the market's prior belief about a firm's value is a uniform distribution on the interval $[\underline{x}, \bar{x}]$, and its posterior belief on the firm value is uniform on a sub-interval in the equilibrium partition, the number of intervals in the equilibrium partition reflects the precision of information that is communicated by managers' disclosures. The more intervals in the equilibrium partition, the more precisely the market can learn about the firm value after observing the disclosures. Hence, the maximum size of equilibrium corresponds to the highest precision of information that can be communicated to the market for a given context. The rest of the paper focuses on the equilibrium of the maximum size.

\footnotetext{
${ }^{13}$ Uniqueness means that the set of partitioning points is unique. The message sent by managers with a type on a given interval could be any value on the interval, but we do not consider the same partition of types with two different sets of messages as two different equilibria.
} 
The next question is how the litigation mechanism affects the highest precision of information that can be communicated in equilibrium. Intuitively, since the existence of litigation mechanism is to discipline the manager's disclosure of unverifiable information by means of penalties, it seems plausible that the harsher the penalty, the more precise the information should be disclosed. This intuition is confirmed by prior studies that assume an exogenous disclosure penalty for the discrepancy between the disclosure and the realization (of earnings), where the bias in the equilibrium biased strategy is decreasing in the harshness of the penalty (Guttman, Kadan and Kandel, 2006). However, this intuition is not completely right when the disclosure cost is endogenous - the severity of the legal liability enhances the communicated information only when it is below a certain level; beyond that level, more severe legal liability actually hinders the communication about the information. Thus, endogenizing the penalty to misleading disclosures not only leads to a different equilibrium disclosure strategy, but also yields a different prediction of the effect of the penalty on the "quality" of disclosures.

Proposition 4. There exists a $\beta^{*}=\frac{2 \alpha}{\gamma}$, such that the maximum size of equilibrium, $N$, is weakly increasing with the severity of the legal liability, $\beta$, when $\beta \leq \beta^{*}$; and is weakly decreasing in $\beta$ when $\beta \geq \beta^{*}$.

Proof: See the Appendix.

Proposition 4 shows that the most informative communication occurs when the legal liability matches perfectly with the compensation incentive $\beta=\frac{2 \alpha}{\gamma}$ so that the manager's most preferred stock price is exactly equal to the fundamental value of the firm, i.e., $p^{*}(x)=x$. In this case, the manager is willing to tell the truth in the disclosure, and the market trusts the manager's disclosure, because the manager's utility is maximized when the stock price is equal to the truth. Hence, a fully revealing equilibrium exists, i.e., managers' private information is perfectly communicated in equilibrium.

When the legal liability is relatively low compared to the compensation incentive, i.e., when $\beta<\frac{2 \alpha}{\gamma}$, the maximum precision of disclosures increases with the severity of 
the legal liability $\beta$, up to the point where $\beta^{*}=\frac{2 \alpha}{\gamma}$ such that infinite precision is achieved. However, if the severity of the legal liability $\beta$ continues to increase from $\beta^{*}$, the maximum precision of disclosures in equilibrium decreases with $\beta$.

The intuition is as follows. When the legal liability is not too high, it works to partly offset the manager's incentive to opportunistically inflate the stock price. Increasing it decreases the manager's desire to inflate the price, and the disclosure becomes more precise in equilibrium. However, when the legal liability is too high, it imposes excessive litigation risk on the manager, and she would actually like to deflate the firm's stock price. Then the higher the legal liability, the more the manager would like to understate the value of the firm and the less precise the information the manager provides.

When $\beta$ is very low or very high, the incentive of managers to mislead the market is so high that the market is extremely skeptical of managers' disclosures. As a result, no information can be credibly communicated to the market, i.e., the market disregards any disclosure from managers. In this case, there is no informative equilibrium. The following Corollary gives the conditions for the non-existence of an informative equilibrium.

Corollary. If $\varepsilon>\bar{x}-\underline{x}$, then when $\beta \leq \frac{2 \alpha}{\gamma\left(\frac{\bar{x}-\underline{x}}{\varepsilon}+1\right)}$ or $\beta \geq \frac{2 \alpha}{\gamma\left(1-\frac{\bar{x}-\underline{x}}{\varepsilon}\right)}$, there does not exist any informative equilibrium.

Proof: See the Appendix.

Proposition 4 shows how the overall precision of disclosures changes with the severity of the legal liability, and that the way in which the legal liability affects the precision of disclosures is different in the two regions of the severity where $\beta<\beta^{*}$ and $\beta>\beta^{*}$. It turns out that the pattern of the relative precision of disclosures across different types of managers is also different in these two scenarios. When $\beta<\beta^{*}$, the precision of disclosures is weakly decreasing in the type of managers, and when $\beta>$ 
$\beta^{*}+\frac{\Delta}{\gamma}$, where $\Delta=\frac{\left(\frac{\gamma c}{2 \varepsilon}\right)^{2}}{2 \alpha}$, the precision of disclosures is weakly increasing in the type of managers.

Proposition 5. Let $x=\left\{x_{0}, x_{1}, \cdots x_{N}\right\}$ be an equilibrium partition with $x_{0}=\underline{x}$ and $x_{N}=\bar{x}$. Let $l_{i}=x_{i}-x_{i-1}$ be the length of the $i$ th interval in partition $x$ for $i=1,2, \cdots N$. Then $l_{i}$ is increasing in $i$ when $\beta<\frac{2 \alpha}{\gamma}$, and decreasing in $i$ when $\beta>\frac{2 \alpha+\Delta}{\gamma}$, where $\Delta=\frac{\left(\frac{\gamma c}{2 \varepsilon}\right)^{2}}{2 \alpha}$.

Proof: See the Appendix.

Proposition 5 shows that when $\beta<\beta^{*}$, lower type managers' disclosures are more precise than higher type managers' disclosures, whereas when $\beta>\beta^{*}+\frac{\Delta}{\gamma}$, higher type managers' disclosures are more precise than lower type managers' disclosures. Intuitively, when the legal liability is low, managers have a net incentive to over-report and inflate the stock price, and thus more favorable disclosures do not have as much information content as less favorable disclosures. However, when the legal liability is high, managers have a net incentive to under-report and deflate the stock price, and thus more favorable disclosures are more informative than less favorable disclosures.

More specifically, the partition in equilibrium represents a set of pools that the managers are willing to form, and the size of a pool then maps into the information content of the disclosure by the pool of managers. The larger the pool, the less information content its disclosure has. To an extreme, when all managers are willing to pool together, then their disclosure does not have any information content.

When $\beta<\beta^{*}$, the severity of the legal liability is not high enough so that managers still prefer to have a higher stock price than their fundamental values; hence, they have a tendency to pool with higher types. As a result, higher type pools are larger than lower type pools. When a higher type pool is larger, the information in its disclosure, which is the average fundamental value of the pool, is less informative about the 
fundamental value of each individual firm than that in the disclosure of a lower type pool, which is in a smaller size.

When $\beta>\beta^{*}+\frac{\Delta}{\gamma}$, the severity of the legal liability is so high that managers prefer a lower stock price than their fundamental values; hence, they have a tendency to pool with lower types. As a result, lower type pools are larger than higher type pools. When a lower type pool is larger, its disclosure has less information content than the disclosure of a higher type pool, which is in a smaller size.

Giger et. al (2009) model conservative accounting as an information system in which good signals are more informative than bad signals. In this sense, high legal liabilities make managers' voluntary disclosures exhibit an informational property that resembles a conservative accounting system, whereas low legal liabilities make the disclosures exhibit an informational property that resembles a liberal accounting system.

This result generates a prediction that can be empirically tested. Note that the disclosure from the lowest type pool represents bad news in the sense that the information on the fundamental value of the firm is worse than the market's prior belief, whereas the disclosure from the highest type pool represents good news because the information on the fundamental value is better than the prior belief. Hence, Proposition 5 predicts that when the legal liability is high, good news is more precise than bad news; and when the legal liability is low, bad news is more precise than good news. 


\section{Conclusion}

Managers make voluntary disclosures to communicate their private information to the market and influence the stock price. When their personal benefit is related to the stock price, shareholder litigation is an important mechanism to discipline their voluntary disclosures. Under Rule 10b-5 of the Securities Exchange Act of 1934, shareholders can sue both the firm and the manager if they suffer damages because the manager's disclosure was misleading and inflated the stock price. When the legal liability in a lawsuit is based on the actual damages that shareholders suffer, as is the case for Rule 10b-5 lawsuits, managers' disclosures, in general, do not reveal their information completely. In particular, managers' disclosures are an interval in which their information lies. Because the information communicated to the market is vague, the stock price is not always true to the manager's information, and some firms are necessarily over-priced. The over-pricing rationalizes shareholders' claims of damages and could result in lawsuits.

Under the discipline of such legal liability, managers' disclosures are indeed credible and informative. The disclosures are credible in the sense that managers' information is always contained within the intervals that they disclose to the market. The disclosures are also informative and move the stock price because they provide information that updates the market's belief about the firm's value. However, the legal liability that is based on actual damages can hardly implement precise disclosures managers' disclosures almost never fully reveal their information.

The effect of legal liability on the precision of managers' disclosures is nonmonotone. In particular, the precision of managers' disclosures increases with the severity of the legal liability only when it is below a certain level. Beyond that level, the precision is reduced by further increases in the severity. Thus, although legal liability disciplines voluntary disclosures by means of a penalty, it is not the case that the harsher the penalty, the better it disciplines disclosures.

The severity of the legal liability also affects the comparative information content of good news and bad news. When legal liability is low, bad news disclosures have more information content than good news; when legal liability is high, the converse is true. 
Interestingly, low legal liability makes the informational property of voluntary disclosures similar to a liberal accounting system, while high legal liability renders the informational property of voluntary disclosures more like a conservative accounting system.

Since the focus of this paper is the effect of legal liability on the information content of disclosures that are actually made, managers' decision on whether to make a disclosure is trivial in the model. ${ }^{14}$ Trueman (1997) studies the effect of shareholder litigation on managers' decision to withhold information under the assumption that the manager's true information can be detected with a positive probability. A further study on the same question under the assumption of non-verifiability of managers' information requires a different model, and is out of the scope of this paper.

${ }^{14}$ The off-equilibrium belief is that no disclosure firms are priced at the lowest value. Therefore, all managers are willing to make a disclosure. 


\section{Bibliography}

Beyer, A. "Capital Market Prices, Management Forecasts, and Earnings Management." The

Accounting Review 84 (2009): 1713-1747.

Beyer, A., and I. Guttman. "The Effect of Trading Volume on Analysts' Forecast Bias." The Accounting Review 86 (2011): 451-481.

Caskey, Judson. “The Pricing Effects of Securities Class Action Lawsuits and Litigation Insurance.” Journal of Law, Economics, and Organization 30 (2014): 493-532.

Choi, S. "The Evidence on Securities Class Actions." Vanderbilt Law Review 57 (2004): 1465-1525.

Crawford, V., and J. Sobel. "Strategic Information Transmission." Econometrica 50 (1982): 1431-1451.

Donelson, D., and J. Hopkins. "Large Market Declines and Securities Litigation: Implications for Disclosing Adverse Earnings News." Management Science, Forthcoming (2016).

Donelson, D., J. Hopkins, and C. Yust. "The Role of D\&O Insurance in Securities Fraud Class Action Settlements.” Journal of Law and Economics, Forthcoming (2015).

Dye, R. "Disclosure of Nonproprietary Information.” Journal of Accounting Research 23 (1985): 123-145.

. "Voluntary Disclosure and the Duty to Disclose." Working paper, Northwestern University, 2014.

. "Optimal Disclosure Decisions When There are Penalties for Nondisclosure."

Working paper, Northwestern University, 2015.

Einhorn, E., and A. Ziv. "Biased Voluntary Disclosure." Review of Accounting Studies 17 (2012): 420-442.

Evans III, J., and S. Sridhar. "Disclosure-Disciplining Mechanisms: Capital Markets, Product Markets, and Shareholder Litigation." The Accounting Review 77 (2002): 595626.

Fischer, P., and P. Stocken. "Imperfect Information and Credible Communication." Journal of Accounting Research 39 (2001): 119-134. 
Fischer, P., and R. Verrecchia. "Reporting Bias.” The Accounting Review 75 (2000): 229245.

Fletcher III, C. “The 'In Connection With' Requirement of Rule10b-5.” Pepperdine Law Review (1989): 913-983.

Francis, J., D. Philbrick, and K. Schipper. "Shareholder Litigation and Corporate Disclosures." Journal of Accounting Research 32 (1994): 137-164.

Gigler, F. "Self-enforcing Voluntary Disclosures." Journal of Accounting Research 32 (1994): 224-240.

Gigler, F., C. Kanodia, H. Sapra, and R. Venugopalan. "Accounting Conservatism and the Efficiency of Debt Contracts." Journal of Accounting Research 47 (2009): 767 797.

Grossman, S. "The Informational Role of Warrantees and Private Disclosure about Product Quality.” Journal of Law and Economics 24 (1981): 461-483.

Guttman, I., O. Kadan, and E. Kandel. "A Rational Expectations Theory of Kinks in Financial Reporting." The Accounting Review 81 (2006): 811-848.

Jovanovic, B., 1982. Truthful Disclosure of Information. The Bell Journal of Economics $13,36-44$.

Jung, Y., and W. Kwon. "Disclosure When the Market is Unsure of Information Endowment of Managers.” Journal of Accounting Research 26 (1988): 146-153.

Kaufman, M., and J. Wunderlich. "The Unjustified Judicial Creation of Class Certification Merits Trials in Securities Fraud Actions." University of Michigan Journal of Law Reform 43 (2009): 323-382.

Klausner, M., and J. Hegland. "How Protective is D\&O Insurance in Securities Class Actions? - Part I.” PLUS Journal 23 (2010): 1-4.

Laux, V., and P. Stocken. "Managerial Reporting, Overoptimism, and Litigation Risk." Journal of Accounting and Economics 53 (2012): 577-591.

Milgrom, P. "Good News and Bad News: Representation Theorems and Applications." The Bell Journal of Economics 12 (1981): 380-391.

Nan, L., and X. Wen. "Scrutiny and Information Influencing." Working paper, Purdue University and Texas Christian University, 2015. 
NERA Economic Consulting. 2015. "Recent Trends in Securities Class Action Litigation: 2014 Full-Year Review."

Newman, P., and R. Sansing. "Disclosure Policies with Multiple Users." Journal of Accounting Research 31 (1993): 92-112.

Skinner, D. "Earnings Disclosures and Stockholder Lawsuits." Journal of Accounting and Economics 23 (1997): 249-282.

Spindler, J. "Vicarious liability for bad corporate governance: Are we wrong about 10b5?" American Law and Economics Review 13 (2011): 359-401.

Stocken, P. "Credibility of Voluntary Disclosure." Rand Journal of Economics 31 (2000): 359-374.

Trueman, B. "Managerial Disclosures and Shareholder Litigation." Review of Accounting Studies 2 (1997): 181-199.

Verrecchia, R. "Discretionary Disclosure." Journal of Accounting and Economics 5 (1983): 179-194. 


\section{Appendix}

\section{Proof for Lemma 4:}

Equation (14) is a second-order difference equation that defines a unique sequence of $x_{i}$ 's for any given $x_{1}$, and each element $x_{i}$ in the sequence is a continuous function of $x_{1}$, denoting $x_{i}\left(x_{1}\right)$.

Consider the case when $\alpha>\frac{\gamma \beta}{2}$, i.e., $p^{*}(x)>x$.

First, examine the case where $x_{1}=x_{0}=\underline{x}$. Take $i=1$ for equation (14), we have $U\left(p_{1}, x_{1}\right)=U\left(p_{2}, x_{1}\right)$, where $p_{1}=x_{1}$, and $p_{2}=\frac{x_{1}+x_{2}}{2}$. Given that $p^{*}(x)>x$ for any $x$, and that $p^{*}(x)$ is the single peak of $U(p, x)$, we must have $p_{2}>x_{1}$, hence $x_{2}>x_{1}$.

Second, examine the case where $x_{1}>x_{0}=\underline{x}$. Again, take $i=1$ for equation (14), we have $U\left(p_{1}, x_{1}\right)=U\left(p_{2}, x_{1}\right)$, where $p_{1}=\frac{x_{1}+\underline{x}}{2}<x_{1}$, and $p_{2}=\frac{x_{1}+x_{2}}{2}$. Again given that $p^{*}(x)>x$ for any $x$, we must have $p_{2}>x_{1}$, hence $x_{2}>x_{1}$.

Therefore the second element $x_{2}$ of a solution sequence to equation (14) with $\underline{x}=x_{0} \leq x_{1}$ must be strictly larger than the first element $x_{1}$. By the same argument, it is easy to verify that the solution sequence is an increasing sequence, that is, $x_{i+1}>x_{i}$ for all $i \geq 1$.

For equation (14) to hold, it must be true that $\frac{x_{i-1}+x_{i}}{2}<p^{*}\left(x_{i}\right)<\frac{x_{i}+x_{i+1}}{2}$. However, given that the litigation cost function is a piecewise function, there can be three possible cases, where $x_{i+1}$ is determined by different equations in relationship to $x_{i-1}$ and $x_{i}$. To see this, note that $U_{p}(\bar{p}(x), x)=\alpha-\frac{\gamma \beta}{2 \varepsilon}\left(2 \varepsilon+\frac{c}{\beta}\right)=-\alpha-\frac{\gamma c}{2 \varepsilon}<-\alpha$, $\lim _{p \rightarrow \underline{p}(x)^{+}} U_{p}(p, x)=\alpha-\frac{\gamma \beta}{2 \varepsilon} \cdot \frac{c}{\beta}=\alpha-\frac{\gamma c}{2 \varepsilon}<\alpha$, and $U(p, x)=\alpha p-\frac{\gamma \beta}{4 \varepsilon}\left[(p-x+\varepsilon)^{2}-\right.$ $\left.\left(\frac{c}{\beta}\right)^{2}\right]$ when $p \in[\underline{p}(x), \bar{p}(x)]$, we know that $U\left(p, x_{i}\right)$ is symmetric about $p^{*}\left(x_{i}\right)=x_{i}+$ $\left(\frac{2 \alpha}{\gamma \beta}-1\right) \varepsilon$ between $\underline{p}\left(x_{i}\right)$ and $\hat{p}=x_{i}+\left(\frac{4 \alpha}{\gamma \beta}-1\right) \varepsilon-\frac{c}{\beta}$, where $p^{*}\left(x_{i}\right)<\hat{p}<\bar{p}\left(x_{i}\right)$. Hence, if $\frac{x_{i-1}+x_{i}}{2}<\underline{p}\left(x_{i}\right)$, it must be true that $\frac{x_{i}+x_{i+1}}{2}>\hat{p}$; and if $\underline{p}\left(x_{i}\right)<\frac{x_{i-1}+x_{i}}{2}<$ $p^{*}\left(x_{i}\right)$, it must be true that $p^{*}\left(x_{i}\right)<\frac{x_{i}+x_{i+1}}{2}<\hat{p}$. Thus, there can be three cases of the 
locus of $\frac{x_{i-1}+x_{i}}{2}$ and $\frac{x_{i}+x_{i+1}}{2}$ on the three pieces of the utility function of type $x_{i}$ as shown below. The proof is done in the three cases.

Case (1): $\frac{x_{i-1}+x_{i}}{2}<\underline{p}\left(x_{i}\right)$, and $\frac{x_{i}+x_{i+1}}{2}>\bar{p}\left(x_{i}\right)$.

In this case, equation (14) can be simplified as

$\alpha \cdot \frac{x_{i-1}+x_{i}}{2}=\alpha \cdot \frac{x_{i}+x_{i+1}}{2}-\gamma \beta\left(\frac{x_{i}+x_{i+1}}{2}-x_{i}\right), i \geq 1$

Reorganize the equation, we have

$$
(\gamma \beta-\alpha) x_{i+1}=\gamma \beta x_{i}-\alpha x_{i-1}
$$

Differentiate with respect to $x_{1}$ on both sides, we have

$(\gamma \beta-\alpha) \frac{d x_{i+1}}{d x_{1}}=\gamma \beta \frac{d x_{i}}{d x_{1}}-\alpha \frac{d x_{i-1}}{d x_{1}}$

For $i=1, \frac{d x_{i-1}}{d x_{1}}=\frac{d x_{0}}{d x_{1}}=0, \frac{d x_{i}}{d x_{1}}=\frac{d x_{1}}{d x_{1}}=1$, equation (16) then implies that $(\gamma \beta-\alpha) \frac{d x_{2}}{d x_{1}}=\gamma \beta$, hence $\frac{d x_{2}}{d x_{1}}=\frac{\gamma \beta}{\gamma \beta-\alpha}>1=\frac{d x_{1}}{d x_{1}}$.

For $i \geq 2$, suppose $\frac{d x_{i}}{d x_{1}}>\frac{d x_{i-1}}{d x_{1}} \geq 1$. Then by equation (16), we have $(\gamma \beta-\alpha) \frac{d x_{i+1}}{d x_{1}}>\gamma \beta \frac{d x_{i}}{d x_{1}}-\alpha \frac{d x_{i}}{d x_{1}}=(\gamma \beta-\alpha) \frac{d x_{i}}{d x_{1}}$, hence $\frac{d x_{i+1}}{d x_{1}}>\frac{d x_{i}}{d x_{1}}$.

By induction, we know that $\frac{d x_{i}}{d x_{1}}>1$ for all $i \geq 2$.

Case (2): $\frac{x_{i-1}+x_{i}}{2}<\underline{p}\left(x_{i}\right)$, and $p^{*}\left(x_{i}\right)<\frac{x_{i}+x_{i+1}}{2}<\bar{p}\left(x_{i}\right)$.

In this case, equation (14) can be simplified as

$$
\alpha \cdot \frac{x_{i-1}+x_{i}}{2}=\alpha \cdot \frac{x_{i}+x_{i+1}}{2}-\frac{\gamma \beta}{4 \varepsilon}\left[\left(\frac{x_{i+1}-x_{i}}{2}+\varepsilon\right)^{2}-\left(\frac{c}{\beta}\right)^{2}\right], i \geq 1
$$

Differentiate the equation with respect to $x_{1}$ on both sides, we have

$$
\frac{\alpha}{2} \cdot\left(\frac{d x_{i}}{d x_{1}}+\frac{d x_{i-1}}{d x_{1}}\right)=\frac{\alpha}{2} \cdot\left(\frac{d x_{i}}{d x_{1}}+\frac{d x_{i+1}}{d x_{1}}\right)-\frac{\gamma \beta}{4 \varepsilon} \cdot\left(\frac{x_{i+1}-x_{i}}{2}+\varepsilon\right)\left(\frac{d x_{i+1}}{d x_{1}}-\frac{d x_{i}}{d x_{1}}\right)
$$

Reorganize the equation, we have

$$
\frac{d x_{i+1}}{d x_{1}}\left(\frac{\gamma \beta}{2 \varepsilon} \cdot\left(\frac{x_{i+1}-x_{i}}{2}+\varepsilon\right)-\alpha\right)=\frac{d x_{i}}{d x_{1}} \cdot \frac{\gamma \beta}{2 \varepsilon} \cdot\left(\frac{x_{i+1}-x_{i}}{2}+\varepsilon\right)-\frac{d x_{i-1}}{d x_{1}} \cdot \alpha
$$

Given that $p^{*}\left(x_{i}\right)<\hat{p}<\frac{x_{i}+x_{i+1}}{2}<\bar{p}\left(x_{i}\right)$, we know that $U_{p}\left(\frac{x_{i}+x_{i+1}}{2}, x_{i}\right)<0$, i.e., $\alpha-\frac{\gamma \beta}{2 \varepsilon} \cdot\left(\frac{x_{i+1}-x_{i}}{2}+\varepsilon\right)<0$. Hence, $\frac{\gamma \beta}{2 \varepsilon} \cdot\left(\frac{x_{i+1}-x_{i}}{2}+\varepsilon\right)>\alpha>0$ for all $i \geq 1$.

For $i=1, \frac{d x_{i-1}}{d x_{1}}=\frac{d x_{0}}{d x_{1}}=0, \frac{d x_{i}}{d x_{1}}=\frac{d x_{1}}{d x_{1}}=1$, plug into equation (17), we have 
$\frac{d x_{2}}{d x_{1}}=\frac{\frac{\gamma \beta}{2 \varepsilon} \cdot\left(\frac{x_{2}-x_{1}}{2}+\varepsilon\right)}{\frac{\gamma \beta}{2 \varepsilon} \cdot\left(\frac{x_{2}-x_{1}}{2}+\varepsilon\right)-\alpha}>1=\frac{d x_{1}}{d x_{1}}$

For $i \geq 2$, suppose $\frac{d x_{i}}{d x_{1}}>\frac{d x_{i-1}}{d x_{1}} \geq 1$. Then by equation (17), we have $\frac{d x_{i+1}}{d x_{1}}\left(\frac{\gamma \beta}{2 \varepsilon} \cdot\left(\frac{x_{i+1}-x_{i}}{2}+\varepsilon\right)-\alpha\right)>\frac{d x_{i}}{d x_{1}} \cdot \frac{\gamma \beta}{2 \varepsilon} \cdot\left(\frac{x_{i+1}-x_{i}}{2}+\varepsilon\right)-\frac{d x_{i}}{d x_{1}} \cdot \alpha=\frac{d x_{i}}{d x_{1}}\left(\frac{\gamma \beta}{2 \varepsilon}\right.$. $\left.\left(\frac{x_{i+1}-x_{i}}{2}+\varepsilon\right)-\alpha\right)$, hence $\frac{d x_{i+1}}{d x_{1}}>\frac{d x_{i}}{d x_{1}}>1$.

By induction, we know that $\frac{d x_{i}}{d x_{1}}>1$ for all $i \geq 2$.

Case (3): $\underline{p}\left(x_{i}\right)<\frac{x_{i-1}+x_{i}}{2}<p^{*}\left(x_{i}\right)$, and $p^{*}\left(x_{i}\right)<\frac{x_{i}+x_{i+1}}{2}<\bar{p}\left(x_{i}\right)$.

In this case, equation (14) can be simplified as

$$
\alpha \cdot \frac{x_{i-1}+x_{i}}{2}-\frac{\gamma \beta}{4 \varepsilon}\left[\left(\frac{x_{i-1}-x_{i}}{2}+\varepsilon\right)^{2}-\left(\frac{c}{\beta}\right)^{2}\right]=\alpha \cdot \frac{x_{i}+x_{i+1}}{2}-\frac{\gamma \beta}{4 \varepsilon}\left[\left(\frac{x_{i+1}-x_{i}}{2}+\varepsilon\right)^{2}-\right.
$$

$\left.\left(\frac{c}{\beta}\right)^{2}\right], i \geq 1$

Differentiate the equation with respect to $x_{1}$ on both sides, we have

$\frac{\alpha}{2} \cdot\left(\frac{d x_{i+1}}{d x_{1}}-\frac{d x_{i-1}}{d x_{1}}\right)=\frac{1}{2} \cdot \frac{\gamma \beta}{2 \varepsilon} \cdot\left(\frac{x_{i+1}-x_{i}}{2}+\varepsilon\right) \cdot\left(\frac{d x_{i+1}}{d x_{1}}-\frac{d x_{i}}{d x_{1}}\right)-\frac{1}{2} \cdot \frac{\gamma \beta}{2 \varepsilon} \cdot\left(\frac{x_{i-1}-x_{i}}{2}+\varepsilon\right)\left(\frac{d x_{i-1}}{d x_{1}}-\right.$ $\left.\frac{d x_{i}}{d x_{1}}\right)$

Reorganize the equation, we have

$$
\begin{aligned}
& \frac{d x_{i+1}}{d x_{1}}\left(\frac{\gamma \beta}{2 \varepsilon} \cdot\left(\frac{x_{i+1}-x_{i}}{2}+\varepsilon\right)-\alpha\right)=\frac{d x_{i}}{d x_{1}}\left(\frac{\gamma \beta}{2 \varepsilon} \cdot\left(\frac{x_{i+1}-x_{i}}{2}+\varepsilon\right)-\frac{\gamma \beta}{2 \varepsilon} \cdot\left(\frac{x_{i-1}-x_{i}}{2}+\varepsilon\right)\right)- \\
& \frac{d x_{i-1}}{d x_{1}}\left(\alpha-\frac{\gamma \beta}{2 \varepsilon} \cdot\left(\frac{x_{i-1}-x_{i}}{2}+\varepsilon\right)\right)
\end{aligned}
$$

Given $\underline{p}\left(x_{i}\right)<\frac{x_{i-1}+x_{i}}{2}<p^{*}\left(x_{i}\right)$ and $p^{*}\left(x_{i}\right)<\frac{x_{i}+x_{i+1}}{2}<\bar{p}\left(x_{i}\right)$, we know that $U_{p}\left(\frac{x_{i-1}+x_{i}}{2}, x_{i}\right)>0$, and $U_{p}\left(\frac{x_{i}+x_{i+1}}{2}, x_{i}\right)<0$, i.e., $\alpha-\frac{\gamma \beta}{2 \varepsilon} \cdot\left(\frac{x_{i-1}-x_{i}}{2}+\varepsilon\right)>0$, and $\alpha-\frac{\gamma \beta}{2 \varepsilon} \cdot\left(\frac{x_{i+1}-x_{i}}{2}+\varepsilon\right)<0$. Hence, $\frac{\gamma \beta}{2 \varepsilon} \cdot\left(\frac{x_{i-1}-x_{i}}{2}+\varepsilon\right)<\alpha<\frac{\gamma \beta}{2 \varepsilon} \cdot\left(\frac{x_{i+1}-x_{i}}{2}+\varepsilon\right)$ for all $i \geq 1$.

For $i=1, \frac{d x_{i-1}}{d x_{1}}=\frac{d x_{0}}{d x_{1}}=0, \frac{d x_{i}}{d x_{1}}=\frac{d x_{1}}{d x_{1}}=1$, plug into equation (18), we have

$$
\frac{d x_{2}}{d x_{1}}=\frac{\frac{\gamma \beta}{2 \varepsilon} \cdot\left(\frac{x_{2}-x_{1}}{2}+\varepsilon\right)-\frac{\gamma \beta}{2 \varepsilon} \cdot\left(\frac{x_{0}-x_{1}}{2}+\varepsilon\right)}{\frac{\gamma \beta}{2 \varepsilon} \cdot\left(\frac{x_{2}-x_{1}}{2}+\varepsilon\right)-\alpha}>1=\frac{d x_{1}}{d x_{1}}
$$


For $i \geq 2$, suppose $\frac{d x_{i}}{d x_{1}}>\frac{d x_{i-1}}{d x_{1}} \geq 1$. Then by equation (18), we have

$$
\begin{aligned}
& \frac{d x_{i+1}}{d x_{1}}\left(\frac{\gamma \beta}{2 \varepsilon} \cdot\left(\frac{x_{i+1}-x_{i}}{2}+\varepsilon\right)-\alpha\right)>\frac{d x_{i}}{d x_{1}}\left(\frac{\gamma \beta}{2 \varepsilon} \cdot\left(\frac{x_{i+1}-x_{i}}{2}+\varepsilon\right)-\frac{\gamma \beta}{2 \varepsilon} \cdot\left(\frac{x_{i-1}-x_{i}}{2}+\varepsilon\right)\right)- \\
& \frac{d x_{i}}{d x_{1}}\left(\alpha-\frac{\gamma \beta}{2 \varepsilon} \cdot\left(\frac{x_{i-1}-x_{i}}{2}+\varepsilon\right)\right)=\frac{d x_{i}}{d x_{1}}\left(\frac{\gamma \beta}{2 \varepsilon} \cdot\left(\frac{x_{i+1}-x_{i}}{2}+\varepsilon\right)-\alpha\right), \text { hence, } \frac{d x_{i+1}}{d x_{1}}>\frac{d x_{i}}{d x_{1}}>1 .
\end{aligned}
$$

By induction, we know that $\frac{d x_{i}}{d x_{1}}>1$ for all $i \geq 2$.

Now consider the case when $\alpha<\frac{\gamma \beta}{2}$, i.e., $p^{*}(x)<x$.

First, examine the case where $x_{1}^{\prime}=x_{0}^{\prime}=\bar{x}$. Take $i=1$ for equation (9), we have $U\left(p_{1}, x_{1}\right)=U\left(p_{2}, x_{1}\right)$, where $p_{1}=x_{1}^{\prime}$, and $p_{2}=\frac{x_{1}^{\prime}+x_{2}^{\prime}}{2}$. Given that $p^{*}(x)<x$ for any $x$, and that $p^{*}(x)$ is the single peak of $U(p, x)$, we must have $p_{2}<x_{1}^{\prime}$, hence $x_{2}^{\prime}>x_{1}^{\prime}$.

Second, examine the case where $x_{1}^{\prime}>x_{0}^{\prime}=\bar{x}$. Again, take $i=1$ for equation (9), we have $U\left(p_{1}, x_{1}\right)=U\left(p_{2}, x_{1}\right)$, where $p_{1}=\frac{x_{1}^{\prime}+\bar{x}}{2}>x_{1}^{\prime}$, and $p_{2}=\frac{x_{1}^{\prime}+x_{2}^{\prime}}{2}$. Again, given that $p^{*}(x)<x$ for any $x$, we must have $p_{2}>x_{1}^{\prime}$, hence $x_{2}^{\prime}<x_{1}^{\prime}$.

Therefore, the second element $x_{2}^{\prime}$ of a solution sequence to equation (9) with $\bar{x}=x_{0}^{\prime} \geq x_{1}^{\prime}$ must be strictly smaller than the first element $x_{1}^{\prime}$. By the same argument, it is easy to verify that the solution sequence is an increasing sequence, that is, $x_{i+1}^{\prime}>x_{i}^{\prime}$ for all $i \geq 1$.

For equation (9) to hold, it must be true that $\frac{x_{i}^{\prime}+x_{i+1}^{\prime}}{2}<p^{*}\left(x_{i}^{\prime}\right)<\frac{x_{i-1}^{\prime}+x_{i}^{\prime}}{2}$. Again, there can be three cases, and the proof is done in three cases.

Case (1): $\frac{x_{i}^{\prime}+x_{i+1}^{\prime}}{2}<\underline{p}\left(x_{i}^{\prime}\right)$, and $\frac{x_{i-1}^{\prime}+x_{i}^{\prime}}{2}>\bar{p}\left(x_{i}^{\prime}\right)$.

In this case, equation (9) can be simplified as

$\alpha \cdot \frac{x_{i}^{\prime}+x_{i+1}^{\prime}}{2}=\alpha \cdot \frac{x_{i-1}^{\prime}+x_{i}^{\prime}}{2}-\gamma \beta\left(\frac{x_{i}^{\prime}+x_{i+1}^{\prime}}{2}-x_{i}^{\prime}\right), i \geq 1$

Reorganize the equation, we have

$$
\alpha x_{i+1}^{\prime}=\gamma \beta x_{i}^{\prime}-(\gamma \beta-\alpha) x_{i-1}^{\prime}
$$

Differentiate with respect to $x_{1}^{\prime}$ on both sides, we have

$$
\alpha \frac{d x_{i+1}^{\prime}}{d x_{1}^{\prime}}=\gamma \beta \frac{d x_{i}^{\prime}}{d x_{1}^{\prime}}-(\gamma \beta-\alpha) \frac{d x_{i-1}^{\prime}}{d x_{1}^{\prime}}
$$


For $i=1, \frac{d x_{i-1}^{\prime}}{d x_{1}^{\prime}}=\frac{d x_{0}^{\prime}}{d x_{1}^{\prime}}=0, \frac{d x_{i}^{\prime}}{d x_{1}^{\prime}}=\frac{d x_{1}^{\prime}}{d x_{1}^{\prime}}=1$, equation (19) then implies that $\alpha \frac{d x_{2}^{\prime}}{d x_{1}^{\prime}}=\gamma \beta$, hence $\frac{d x_{2}^{\prime}}{d x_{1}^{\prime}}>1=\frac{d x_{1}^{\prime}}{d x_{1}^{\prime}}$.

For $i \geq 2$, suppose $\frac{d x_{i}^{\prime}}{d x_{1}^{\prime}}>\frac{d x_{i-1}^{\prime}}{d x_{1}^{\prime}} \geq 1$. Then by equation (19), we have

$\alpha \frac{d x_{i+1}^{\prime}}{d x_{1}^{\prime}}>\gamma \beta \frac{d x_{i}^{\prime}}{d x_{1}^{\prime}}-(\gamma \beta-\alpha) \frac{d x_{i}^{\prime}}{d x_{1}^{\prime}}=\alpha \frac{d x_{i}^{\prime}}{d x_{1}^{\prime}}$, hence $\frac{d x_{i+1}}{d x_{1}^{\prime}}>\frac{d x_{i}^{\prime}}{d x_{1}^{\prime}}$.

By induction, we know that $\frac{d x_{i}^{\prime}}{d x_{1}^{\prime}}>1$ for all $i \geq 2$.

Case (2): $\frac{x_{i}^{\prime}+x_{i+1}^{\prime}}{2}<\underline{p}\left(x_{i}^{\prime}\right)$, and $p^{*}\left(x_{i}^{\prime}\right)<\frac{x_{i-1}^{\prime}+x_{i}^{\prime}}{2}<\bar{p}\left(x_{i}^{\prime}\right)$.

In this case, equation (9) can be simplified as

$\alpha \cdot \frac{x_{i}^{\prime}+x_{i+1}^{\prime}}{2}=\alpha \cdot \frac{x_{i-1}^{\prime}+x_{i}^{\prime}}{2}-\frac{\gamma \beta}{4 \varepsilon}\left[\left(\frac{x_{i-1}^{\prime}-x_{i}^{\prime}}{2}+\varepsilon\right)^{2}-\left(\frac{c}{\beta}\right)^{2}\right], i \geq 1$

Differentiate the equation with respect to $x_{1}^{\prime}$ on both sides, we have $\frac{\alpha}{2} \cdot\left(\frac{d x_{i}^{\prime}}{d x_{1}^{\prime}}+\frac{d x_{i+1}^{\prime}}{d x_{1}^{\prime}}\right)=\frac{\alpha}{2} \cdot\left(\frac{d x_{i-1}^{\prime}}{d x_{1}^{\prime}}+\frac{d x_{i}^{\prime}}{d x_{1}^{\prime}}\right)-\frac{1}{2} \cdot \frac{\gamma \beta}{2 \varepsilon} \cdot\left(\frac{x_{i-1}^{\prime}-x_{i}^{\prime}}{2}+\varepsilon\right)\left(\frac{d x_{i-1}^{\prime}}{d x_{1}^{\prime}}-\frac{d x_{i}^{\prime}}{d x_{1}^{\prime}}\right)$

Reorganize the equation, we have

$\alpha \cdot \frac{d x_{i+1}^{\prime}}{d x_{1}^{\prime}}=\frac{d x_{i}^{\prime}}{d x_{1}^{\prime}} \cdot \frac{\gamma \beta}{2 \varepsilon} \cdot\left(\frac{x_{i-1}^{\prime}-x_{i}^{\prime}}{2}+\varepsilon\right)-\frac{d x_{i-1}^{\prime}}{d x_{1}^{\prime}} \cdot\left(\frac{\gamma \beta}{2 \varepsilon} \cdot\left(\frac{x_{i-1}^{\prime}-x_{i}^{\prime}}{2}+\varepsilon\right)-\alpha\right)$

Given that $p^{*}\left(x_{i}^{\prime}\right)<\frac{x_{i-1}^{\prime}+x_{i}^{\prime}}{2}<\bar{p}\left(x_{i}^{\prime}\right)$, we know that $U_{p}\left(\frac{x_{i-1}^{\prime}+x_{i}^{\prime}}{2}, x_{i}^{\prime}\right)<0$, i.e., $\alpha-\frac{\gamma \beta}{2 \varepsilon} \cdot\left(\frac{x_{i-1}^{\prime}-x_{i}^{\prime}}{2}+\varepsilon\right)<0$. Hence, $\frac{\gamma \beta}{2 \varepsilon} \cdot\left(\frac{x_{i-1}^{\prime}-x_{i}^{\prime}}{2}+\varepsilon\right)>\alpha>0$ for all $i \geq 1$.

For $i=1, \frac{d x_{i-1}^{\prime}}{d x_{1}^{\prime}}=\frac{d x_{0}}{d x_{1}^{\prime}}=0, \frac{d x_{i}^{\prime}}{d x_{1}^{\prime}}=\frac{d x_{1}^{\prime}}{d x_{1}^{\prime}}=1$, plug into equation (20), we have $\frac{d x_{2}^{\prime}}{d x_{1}^{\prime}}=\frac{\frac{\gamma \beta}{2 \varepsilon} \cdot\left(\frac{x_{0}^{\prime}-x_{1}^{\prime}}{2}+\varepsilon\right)}{\alpha}>1=\frac{d x_{1}^{\prime}}{d x_{1}^{\prime}}$

For $i \geq 2$, suppose $\frac{d x_{i}^{\prime}}{d x_{1}^{\prime}}>\frac{d x_{i-1}^{\prime}}{d x_{1}^{\prime}} \geq 1$. Then by equation (20), we have $\alpha \cdot \frac{d x_{i+1}^{\prime}}{d x_{1}^{\prime}}>\frac{d x_{i}^{\prime}}{d x_{1}^{\prime}} \cdot \frac{\gamma \beta}{2 \varepsilon} \cdot\left(\frac{x_{i-1}^{\prime}-x_{i}^{\prime}}{2}+\varepsilon\right)-\frac{d x_{i}^{\prime}}{d x_{1}^{\prime}} \cdot\left(\frac{\gamma \beta}{2 \varepsilon} \cdot\left(\frac{x_{i-1}^{\prime}-x_{i}^{\prime}}{2}+\varepsilon\right)-\alpha\right)=\alpha \cdot \frac{d x_{i}^{\prime}}{d x_{1}^{\prime}}$, hence $\frac{d x_{i+1}^{\prime}}{d x_{1}^{\prime}}>\frac{d x_{i}^{\prime}}{d x_{1}^{\prime}}>1$.

By induction, we know that $\frac{d x_{i}^{\prime}}{d x_{1}^{\prime}}>1$ for all $i \geq 2$. 
Case (3): $\underline{p}\left(x_{i}^{\prime}\right)<\frac{x_{i}^{\prime}+x_{i+1}^{\prime}}{2}<p^{*}\left(x_{i}^{\prime}\right)$, and $p^{*}\left(x_{i}^{\prime}\right)<\frac{x_{i-1}^{\prime}+x_{i}^{\prime}}{2}<\bar{p}\left(x_{i}^{\prime}\right)$.

In this case, equation (9) can be simplified as $\alpha \cdot \frac{x_{i}^{\prime}+x_{i+1}^{\prime}}{2}-\frac{\gamma \beta}{4 \varepsilon}\left[\left(\frac{x_{i+1}^{\prime}-x_{i}^{\prime}}{2}+\varepsilon\right)^{2}-\left(\frac{c}{\beta}\right)^{2}\right]=\alpha \cdot \frac{x_{i-1}^{\prime}+x_{i}^{\prime}}{2}-\frac{\gamma \beta}{4 \varepsilon}\left[\left(\frac{x_{i-1}^{\prime}-x_{i}^{\prime}}{2}+\varepsilon\right)^{2}-\left(\frac{c}{\beta}\right)^{2}\right], i \geq 1$

Differentiate the equation with respect to $x_{1}$ on both sides, we have

$$
\frac{\alpha}{2} \cdot\left(\frac{d x_{i+1}^{\prime}}{d x_{1}^{\prime}}-\frac{d x_{i-1}^{\prime}}{d x_{1}^{\prime}}\right)=\frac{1}{2} \cdot \frac{\gamma \beta}{2 \varepsilon} \cdot\left(\frac{x_{i+1}^{\prime}-x_{i}^{\prime}}{2}+\varepsilon\right) \cdot\left(\frac{d x_{i+1}^{\prime}}{d x_{1}^{\prime}}-\frac{d x_{i}^{\prime}}{d x_{1}^{\prime}}\right)-\frac{1}{2} \cdot \frac{\gamma \beta}{2 \varepsilon} \cdot\left(\frac{x_{i-1}^{\prime}-x_{i}^{\prime}}{2}+\right.
$$

$\varepsilon)\left(\frac{d x_{i-1}^{\prime}}{d x_{1}^{\prime}}-\frac{d x_{i}^{\prime}}{d x_{1}^{\prime}}\right)$

Reorganize the equation, we have

$$
\begin{aligned}
& \frac{d x_{i+1}^{\prime}}{d x_{1}^{\prime}}\left(\alpha-\frac{\gamma \beta}{2 \varepsilon} \cdot\left(\frac{x_{i+1}^{\prime}-x_{i}^{\prime}}{2}+\varepsilon\right)\right)=\frac{d x_{i}^{\prime}}{d x_{1}^{\prime}}\left(\frac{\gamma \beta}{2 \varepsilon} \cdot\left(\frac{x_{i-1}^{\prime}-x_{i}^{\prime}}{2}+\varepsilon\right)-\frac{\gamma \beta}{2 \varepsilon} \cdot\left(\frac{x_{i+1}^{\prime}-x_{i}^{\prime}}{2}+\varepsilon\right)\right)- \\
& \frac{d x_{i-1}^{\prime}}{d x_{1}^{\prime}}\left(\frac{\gamma \beta}{2 \varepsilon} \cdot\left(\frac{x_{i-1}^{\prime}-x_{i}^{\prime}}{2}+\varepsilon\right)-\alpha\right)
\end{aligned}
$$

Given that $\underline{p}\left(x_{i}^{\prime}\right)<\frac{x_{i}^{\prime}+x_{i+1}^{\prime}}{2}<p^{*}\left(x_{i}^{\prime}\right)<\frac{x_{i-1}^{\prime}+x_{i}^{\prime}}{2}<\bar{p}\left(x_{i}^{\prime}\right)$, we know that $U_{p}\left(\frac{x_{i+1}^{\prime}+x_{i}^{\prime}}{2}, x_{i}^{\prime}\right)>0$ and $U_{p}\left(\frac{x_{i}^{\prime}+x_{i-1}^{\prime}}{2}, x_{i}^{\prime}\right)<0$, i.e., $\alpha-\frac{\gamma \beta}{2 \varepsilon} \cdot\left(\frac{x_{i+1}^{\prime}-x_{i}^{\prime}}{2}+\varepsilon\right)>0$, and $\alpha-\frac{\gamma \beta}{2 \varepsilon} \cdot\left(\frac{x_{i-1}^{\prime}-x_{i}^{\prime}}{2}+\varepsilon\right)<0$. Hence, $\frac{\gamma \beta}{2 \varepsilon} \cdot\left(\frac{x_{i+1}^{\prime}-x_{i}^{\prime}}{2}+\varepsilon\right)<\alpha<\frac{\gamma \beta}{2 \varepsilon} \cdot\left(\frac{x_{i-1}^{\prime}-x_{i}^{\prime}}{2}+\varepsilon\right)$ for all $i \geq 1$.

For $i=1, \frac{d x_{i-1}^{\prime}}{d x_{1}^{\prime}}=\frac{d x_{0}}{d x_{1}^{\prime}}=0, \frac{d x_{i}^{\prime}}{d x_{1}^{\prime}}=\frac{d x_{1}^{\prime}}{d x_{1}^{\prime}}=1$, plug into equation (21), we have

$$
\frac{d x_{2}^{\prime}}{d x_{1}^{\prime}}=\frac{\frac{\gamma \beta}{2 \varepsilon} \cdot\left(\frac{x_{0}^{\prime}-x_{1}^{\prime}}{2}+\varepsilon\right)-\frac{\gamma \beta}{2 \varepsilon} \cdot\left(\frac{x_{2}^{\prime}-x_{1}^{\prime}}{2}+\varepsilon\right)}{\alpha-\frac{\gamma \beta}{2 \varepsilon} \cdot\left(\frac{x_{2}^{\prime}-x_{1}^{\prime}}{2}+\varepsilon\right)}>1=\frac{d x_{1}^{\prime}}{d x_{1}^{\prime}}
$$

For $i \geq 2$, suppose $\frac{d x_{i}^{\prime}}{d x_{1}^{\prime}}>\frac{d x_{i-1}^{\prime}}{d x_{1}^{\prime}} \geq 1$. Then by equation (18), we have

$$
\begin{aligned}
& \frac{d x_{i+1}^{\prime}}{d x_{1}^{\prime}}\left(\alpha-\frac{\gamma \beta}{2 \varepsilon} \cdot\left(\frac{x_{i+1}^{\prime}-x_{i}^{\prime}}{2}+\varepsilon\right)\right)>\frac{d x_{i}^{\prime}}{d x_{1}^{\prime}}\left(\frac{\gamma \beta}{2 \varepsilon} \cdot\left(\frac{x_{i-1}^{\prime}-x_{i}^{\prime}}{2}+\varepsilon\right)-\frac{\gamma \beta}{2 \varepsilon} \cdot\left(\frac{x_{i+1}^{\prime}-x_{i}^{\prime}}{2}+\varepsilon\right)\right)- \\
& \frac{d x_{i}^{\prime}}{d x_{1}^{\prime}}\left(\frac{\gamma \beta}{2 \varepsilon} \cdot\left(\frac{x_{i-1}^{\prime}-x_{i}^{\prime}}{2}+\varepsilon\right)-\alpha\right)=\frac{d x_{i}^{\prime}}{d x_{1}^{\prime}}\left(\alpha-\frac{\gamma \beta}{2 \varepsilon} \cdot\left(\frac{x_{i+1}^{\prime}-x_{i}^{\prime}}{2}+\varepsilon\right)\right), \text { hence } \frac{d x_{i+1}^{\prime}}{d x_{1}^{\prime}}>\frac{d x_{i}^{\prime}}{d x_{1}^{\prime}}>1 .
\end{aligned}
$$

By induction, we know that $\frac{d x_{i}^{\prime}}{d x_{1}^{\prime}}>1$ for all $i \geq 2$.

Q.E.D. 


\section{Proof for Proposition 3:}

Lemma 4 shows that the solution sequences exhibit different patterns when $\alpha>\frac{\gamma \beta}{2}$ than when $\alpha<\frac{\gamma \beta}{2}$. Hence, the proof is done in these two cases.

Case 1. $\alpha>\frac{\gamma \beta}{2}$.

Let $\left\{x_{0}, x_{1}, \cdots, x_{i}, \cdots\right\}$ be the sequence determined by equation (14) with $\underline{x}=x_{0} \leq$ $x_{1} \leq \bar{x}$, then each element $x_{i}\left(x_{1}\right)$ is increasing in $x_{1}$. Let $\underline{x}_{i}=\min _{x_{1} \in[\underline{x}, \bar{x}]} x_{i}\left(x_{1}\right)$, and $\bar{x}_{i}=\max _{x_{1} \in[\underline{x}, \bar{x}]} x_{i}\left(x_{1}\right)$, then $\underline{x}_{i}=x_{i}(\underline{x})$, and $\bar{x}_{i}=x_{i}(\bar{x})$.

By Lemma 4, we have $x_{i}\left(x_{1}\right)>x_{1}$ for all $i>1$, hence $\bar{x}_{i}=x_{i}(\bar{x})>\bar{x}$ for all $i>1$. Let $N=\max \left\{i: \underline{x}_{i} \leq \bar{x}\right\}$, then $N$ is the largest index of the elements that can take value(s) on $[\underline{x}, \bar{x}]$, and we have $\underline{x}_{N} \leq \bar{x}$. Note that $\bar{x}_{i}>\bar{x}$ for all $i>1$ implies $\bar{x}_{N}>\bar{x}$. Hence, $\bar{x} \in\left[\underline{x}_{N}, \bar{x}_{N}\right)$. Given that $x_{N}\left(x_{1}\right)$ is continuous in $x_{1}$, there must be a $x_{1}^{*} \in[\underline{x}, \bar{x}]$ such that $x_{N}\left(x_{1}^{*}\right)=\bar{x}$. This means that there exists a partition of size $N$ in equilibrium. Since $N=\max \left\{i: \underline{x}_{i} \leq \bar{x}\right\}$, we know $\underline{x}_{N+1}>\bar{x}$, which implies that there does not exist an equilibrium partition of a size larger than $N$. Therefore, $N$ is the maximum size of equilibrium partitions.

Given that $x_{i}\left(x_{1}^{*}\right)$ is increasing in $i$, and $x_{N}\left(x_{1}^{*}\right)=\bar{x}$, we have $x_{i}\left(x_{1}^{*}\right)<\bar{x}$ for all $1<i<N$. On the other hand, we know that $\bar{x}_{i}>\bar{x}$ for all $i>1$. Hence $\bar{x} \in\left(x_{i}\left(x_{1}^{*}\right), \bar{x}_{i}\right)$ for all $1<i<N$. Since $x_{i}\left(x_{1}\right)$ is continuous in $x_{1}$, there must exist a $x_{1}^{i} \in\left(x_{1}^{*}, \bar{x}\right)$ for each $1<i<N$ such that $x_{i}\left(x_{1}^{i}\right)=\bar{x}$. This means that for each $1 \leq n \leq N$, there exists an equilibrium of size $n$. The uniqueness of the equilibrium for each size $n$ is guaranteed by the fact that $x_{i}\left(x_{1}\right)$ is strictly increasing in $x_{1}$ for all $i>1$, which is established by Lemma 4.

Case 2. $\alpha<\frac{\gamma \beta}{2}$.

Let $\left\{x_{0}^{\prime}, x_{1}^{\prime}, \ldots, x_{i}^{\prime}, \ldots\right\}$ be the sequence determined by equation (14) with $\bar{x}=x_{0}^{\prime} \geq$ $x_{1}^{\prime} \geq \underline{x}$, then each element $x_{i}^{\prime}\left(x_{1}^{\prime}\right)$ is increasing in $x_{1}$. Let $\underline{x}_{i}^{\prime}=\min _{x_{1}^{\prime} \in[\underline{x}, \bar{x}]} x_{i}^{\prime}\left(x_{1}^{\prime}\right)$, and $\bar{x}_{i}^{\prime}=\max _{x_{1}^{\prime} \in[\underline{x}, \bar{x}]} x_{i}^{\prime}\left(x_{1}^{\prime}\right)$, then $\underline{x}_{i}^{\prime}=x_{i}^{\prime}(\underline{x})$, and $\bar{x}_{i}^{\prime}=x_{i}^{\prime}(\bar{x})$. 
By Lemma 4, we have $x_{i}^{\prime}\left(x_{1}^{\prime}\right)<x_{1}^{\prime}$ for all $i>1$, hence $\underline{x}_{i}^{\prime}=x_{i}^{\prime}(\underline{x})<\underline{x}$ for all $i>1$. Let $N=\max \left\{i: \bar{x}_{i}^{\prime} \geq \underline{x}\right\}$, then $N$ is the largest index of the elements that can take some value(s) on $[\underline{x}, \bar{x}]$, and we have $\bar{x}_{N}^{\prime} \geq \underline{x}$. Note that $\underline{x}_{i}^{\prime}<\underline{x}$ for all $i>1$ implies $\underline{x}_{N}^{\prime}<\underline{x}$. Hence, $\underline{x} \in\left(\underline{x}_{N}^{\prime}, \bar{x}_{N}^{\prime}\right]$. Given that $x_{N}^{\prime}\left(x_{1}^{\prime}\right)$ is continuous in $x_{1}^{\prime}$, there must be a $x_{1}^{\prime *} \in[\underline{x}, \bar{x}]$ such that $x_{N}^{\prime}\left(x_{1}^{\prime *}\right)=\underline{x}$. This means that there exists a partition of size $N$ in equilibrium. Since $N=\max \left\{i: \bar{x}_{i}^{\prime} \geq \underline{x}\right\}$, we know $\bar{x}_{N+1}^{\prime}<\underline{x}$, which implies that there does not exist an equilibrium partition of size larger than $N$. Therefore, $N$ is the maximum size of equilibrium partitions.

Given that $x_{i}^{\prime}\left(x_{1}^{\prime *}\right)$ is increasing in $i$, and $x_{N}^{\prime}\left(x_{1}^{\prime *}\right)=\underline{x}$, we have $x_{i}^{\prime}\left(x_{1}^{\prime *}\right)>\underline{x}$ for all $1<i<N$. On the other hand, we know that $\underline{x}_{i}^{\prime}<\underline{x}$ for all $i>1$. Hence, $\underline{x} \in$ $\left(\underline{x}_{i}^{\prime}, x_{i}^{\prime}\left(x_{1}^{\prime *}\right)\right)$ for all $1<i<N$. Since $x_{i}^{\prime}\left(x_{1}^{\prime}\right)$ is continuous in $x_{1}$, there must exist a $x_{1}^{\prime i} \in\left(\underline{x}, x_{1}^{\prime *}\right)$ for each $1<i<N$ such that $x_{i}^{\prime}\left(x_{1}^{\prime i}\right)=\underline{x}$. This means that for each $1 \leq n \leq N$, there exists an equilibrium of size $n$. The uniqueness of the equilibrium for each size $n$ is guaranteed by the fact that $x_{i}^{\prime}\left(x_{1}^{\prime}\right)$ is strictly increasing in $x_{1}^{\prime}$ for all $i>1$, which is established by Lemma 4.

Q.E.D.

\section{Proof for Proposition 4:}

Denote the maximum size of equilibrium partitions $N(\beta)$ as a function of the harshness measure $\beta$.

First consider the case when $\beta<\frac{2 \alpha}{\gamma}$. We need to prove that $N(\beta)$ is nondecreasing in $\beta$ in this case.

\section{Step 1.}

Let $x\left(n, \beta_{1}\right)$ and $x\left(n, \beta_{2}\right)$ be a sequence of solutions to equation (14) for $\beta=\beta_{1}$ and $\beta=\beta_{2}$ respectively for $i=1,2, \cdots, n$, with $x_{0}\left(n, \beta_{1}\right)=x_{0}\left(n, \beta_{2}\right)=\underline{x}$, and $\beta_{1}<\beta_{2}$.

I first prove that if $x_{n}\left(n, \beta_{1}\right)=x_{n}\left(n, \beta_{2}\right) \leq \bar{x}$, then $x_{i}\left(n, \beta_{1}\right)<x_{i}\left(n, \beta_{2}\right)$ for all $i=1,2, \cdots, n-1$ by induction.

For $n=1$, the lemma is trivial.

For $n=2$, suppose $x_{2}\left(n, \beta_{1}\right)=x_{2}\left(n, \beta_{2}\right) \leq \bar{x}$, but $x_{1}\left(n, \beta_{1}\right) \geq x_{1}\left(n, \beta_{2}\right)$. 


$$
\begin{aligned}
& U\left(\frac{x_{1}\left(n, \beta_{1}\right)+x_{2}\left(n, \beta_{1}\right)}{2}, x_{1}\left(n, \beta_{1}\right), \beta_{2}\right)-U\left(\frac{x+x_{1}\left(n, \beta_{1}\right)}{2}, x_{1}\left(n, \beta_{1}\right), \beta_{2}\right)- \\
& {\left[U\left(\frac{x_{1}\left(n, \beta_{1}\right)+x_{2}\left(n, \beta_{1}\right)}{2}, x_{1}\left(n, \beta_{1}\right), \beta_{1}\right)-U\left(\frac{x+x_{1}\left(n, \beta_{1}\right)}{2}, x_{1}\left(n, \beta_{1}\right), \beta_{1}\right)\right]=}
\end{aligned}
$$

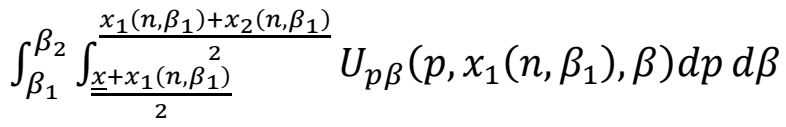

Since $p^{*}\left(x_{1}\left(n, \beta_{1}\right)\right)<\frac{x_{1}\left(n, \beta_{1}\right)+x_{2}\left(n, \beta_{1}\right)}{2}$, and $p^{*}\left(x_{1}\left(n, \beta_{1}\right)\right) \geq x_{1}\left(n, \beta_{1}\right)-\varepsilon+\frac{c}{\beta_{1}}$, we have $\frac{x_{1}\left(n, \beta_{1}\right)+x_{2}\left(n, \beta_{1}\right)}{2}>x_{1}\left(n, \beta_{1}\right)-\varepsilon+\frac{c}{\beta_{1}}$. Given $U_{p \beta}(p, x, \beta) \leq 0$ for any $p$ and $U_{p \beta}(p, x, \beta)<0$ for $p \geq x-\varepsilon+\frac{c}{\beta}$, we have $U_{p \beta}\left(p, x_{1}\left(n, \beta_{1}\right), \beta\right)<0$ for some $p \in$ $\left(\frac{x+x_{1}\left(n, \beta_{1}\right)}{2}, \frac{x_{1}\left(n, \beta_{1}\right)+x_{2}\left(n, \beta_{1}\right)}{2}\right)$ and any $\beta \in\left[\beta_{1}, \beta_{2}\right]$; hence,

$$
\int_{\beta_{1}}^{\beta_{2}} \int_{\frac{x+x_{1}\left(n, \beta_{1}\right)}{2}}^{\frac{x_{1}\left(n, \beta_{1}\right)+x_{2}\left(n, \beta_{1}\right)}{2}} U_{p \beta}\left(p, x_{1}\left(n, \beta_{1}\right), \beta\right) d p d \beta<0 .
$$

Since $U\left(\frac{\underline{x}+x_{1}\left(n, \beta_{1}\right)}{2}, x_{1}\left(n, \beta_{1}\right), \beta_{1}\right)=U\left(\frac{x_{1}\left(n, \beta_{1}\right)+x_{2}\left(n, \beta_{1}\right)}{2}, x_{1}\left(n, \beta_{1}\right), \beta_{1}\right)$, we have

$$
U\left(\frac{x_{1}\left(n, \beta_{1}\right)+x_{2}\left(n, \beta_{1}\right)}{2}, x_{1}\left(n, \beta_{1}\right), \beta_{2}\right)-U\left(\frac{x+x_{1}\left(n, \beta_{1}\right)}{2}, x_{1}\left(n, \beta_{1}\right), \beta_{2}\right)<0 .
$$

On the other hand, let $\hat{x}_{2}$ be the solution to the equation $U\left(\frac{\underline{x}+x_{1}\left(n, \beta_{1}\right)}{2}, x_{1}\left(n, \beta_{1}\right), \beta_{2}\right)=U\left(\frac{x_{1}\left(n, \beta_{1}\right)+x_{2}}{2}, x_{1}\left(n, \beta_{1}\right), \beta_{2}\right)$, then given that $x_{1}\left(n, \beta_{1}\right) \geq$ $x_{1}\left(n, \beta_{2}\right)$ and by Lemma 4 , we have $\hat{x}_{2} \geq x_{2}\left(n, \beta_{2}\right)$. Since $U(p, x, \beta)$ has a single peak, for any $p$ such that $\frac{\underline{x}+x_{1}\left(n, \beta_{1}\right)}{2} \leq p \leq \frac{x_{1}\left(n, \beta_{1}\right)+\hat{x}_{2}}{2}$, it must be true that $U\left(p, x_{1}\left(n, \beta_{1}\right), \beta_{2}\right) \geq$ $U\left(\frac{\underline{x}+x_{1}\left(n, \beta_{1}\right)}{2}, x_{1}\left(n, \beta_{1}\right), \beta_{2}\right)$. Given that $\hat{x}_{2} \geq x_{2}\left(n, \beta_{2}\right)=x_{2}\left(n, \beta_{1}\right)$, we know that $\frac{\underline{x}+x_{1}\left(n, \beta_{1}\right)}{2}<\frac{x_{1}\left(n, \beta_{1}\right)+x_{2}\left(n, \beta_{1}\right)}{2} \leq \frac{x_{1}\left(n, \beta_{1}\right)+\hat{x}_{2}}{2}$. Hence $U\left(\frac{x_{1}\left(n, \beta_{1}\right)+x_{2}\left(n, \beta_{1}\right)}{2}, x_{1}\left(n, \beta_{1}\right), \beta_{2}\right) \geq$ $U\left(\frac{x+x_{1}\left(n, \beta_{1}\right)}{2}, x_{1}\left(n, \beta_{1}\right), \beta_{2}\right)$

However, (22) and (23) contradict each other. Hence, the result is true when $n=2$.

Suppose the result is true for all $n=1,2, \cdots, k-1$. For $n=k$, suppose there exists some $1 \leq j \leq k-1$ such that $x_{j}\left(k, \beta_{1}\right) \geq x_{j}\left(k, \beta_{2}\right)$. Let $l$ be the largest index in those $j$ 's, then $x_{i}\left(k, \beta_{1}\right)<x_{i}\left(k, \beta_{2}\right)$ for all $l<i<k$. 
Define $\Delta U\left(x_{i-1}, x_{i}, x_{i+1}, \beta\right)=U\left(\frac{x_{i}+x_{i+1}}{2}, x_{i}, \beta\right)-U\left(\frac{x_{i-1}+x_{i}}{2}, x_{i}, \beta\right)$ for $\quad$ any $\underline{x} \leq x_{i-1}<x_{i}<x_{i+1} \leq \bar{x}$. Construct a sequence of solutions, $x^{a}=\left(x_{0}^{a}, x_{1}^{a}, \cdots, x_{l}^{a}\right)$, to the equation $\Delta U\left(x_{i-1}, x_{i}, x_{i+1}, \beta_{2}\right)=0$ for $i=1,2, \cdots, l-1$, with $x_{0}^{a}=\underline{x}$, and $x_{1}^{a}=a$. From the proof of Lemma 4 , we know that $x_{l}^{a}$ is continuously increasing in $a$, there must be a $\quad \hat{a} \geq x_{1}\left(k, \beta_{2}\right)$ such that $x_{l}^{\hat{a}}=x_{l}\left(k, \beta_{1}\right) \geq x_{l}\left(k, \beta_{2}\right)$. Since $U_{p}\left(\frac{x_{l}\left(k, \beta_{1}\right)+x}{2}, x_{l}\left(k, \beta_{1}\right), \beta_{1}\right)<0$ for all $x \geq x_{l+1}\left(k, \beta_{1}\right)$, we have $\Delta U_{3}\left(x_{l-1}^{\hat{a}}, x_{l}^{\hat{a}}, x, \beta_{1}\right)=$ $U_{p}\left(\frac{x_{l}\left(k, \beta_{1}\right)+x}{2}, x_{l}\left(k, \beta_{1}\right), \beta_{1}\right) \cdot \frac{1}{2}<0$ for all $x \geq x_{l+1}\left(k, \beta_{1}\right)$.

Given that $x_{l+1}\left(k, \beta_{2}\right)>x_{l+1}\left(k, \beta_{1}\right)$, we have

$$
\Delta U\left(x_{l-1}^{\hat{a}}, x_{l}^{\hat{a}}, x_{l+1}\left(k, \beta_{1}\right), \beta_{1}\right)>\Delta U\left(x_{l-1}^{\hat{a}}, x_{l}^{\hat{a}}, x_{l+1}(k, \beta), \beta_{1}\right)
$$

Recall that $U_{p \beta}(p, x, \beta) \leq 0$ for any $p$ and $U_{p \beta}(p, x, \beta)<0$ for $p \geq x-\varepsilon+\frac{c}{\beta}$. Note that $x_{i}-\varepsilon+\frac{c}{\beta} \leq p^{*}\left(x_{i}\right)<\frac{x_{i}+x_{i+1}}{2}$; hence, $U_{\beta}(p, x, \beta)$ is strictly decreasing in $p$ in a neighborhood of $\frac{x_{i}+x_{i+1}}{2}$, and flat in $p$ elsewhere. Therefore, we have

$$
\begin{gathered}
\frac{d}{d \beta}\left\{\Delta U\left(x_{i-1}, x_{i}, x_{i+1}, \beta\right)\right\}=\frac{d}{d \beta}\left(U\left(\frac{x_{i}+x_{i+1}}{2}, x_{i}, \beta\right)-U\left(\frac{x_{i-1}+x_{i}}{2}, x_{i}, \beta\right)\right)= \\
\frac{d}{d \beta}\left(U\left(\frac{x_{i}+x_{i+1}}{2}, x_{i}, \beta\right)\right)-\frac{d}{d \beta}\left(U\left(\frac{x_{i-1}+x_{i}}{2}, x_{i}, \beta\right)\right)<0 .
\end{gathered}
$$

Note that $x_{l}^{\hat{a}}=x_{l}\left(k, \beta_{1}\right)$, it must be true that $x_{l+1}\left(k, \beta_{1}\right)>x_{l}^{\hat{a}}$. Together with the fact that $x_{l+1}\left(k, \beta_{2}\right) \geq x_{l+1}\left(k, \beta_{1}\right)$, we must have $x_{l+1}\left(k, \beta_{2}\right)>x_{l}^{\hat{a}}>x_{l-1}^{\hat{a}}$. It then follows that

$$
\Delta U\left(x_{l-1}^{\hat{a}}, x_{l}^{\hat{a}}, x_{l+1}\left(k, \beta_{2}\right), \beta_{1}\right)>\Delta U\left(x_{l-1}^{\hat{a}}, x_{l}^{\hat{a}}, x_{l+1}\left(k, \beta_{2}\right), \beta_{2}\right)
$$

Define $p^{*}(x, \beta)=\operatorname{argmax}_{p}\{U(p, x, \beta)\}$. Note that when $\beta<\frac{2 \alpha}{\gamma}, p^{*}(x, \beta)>x$ for any $x$. Since $U_{p}\left(p, x_{l}^{\hat{a}}, \beta_{2}\right)>0$ for all $p<p^{*}\left(x_{l}^{\hat{a}}, \beta_{2}\right)$, and $\frac{x_{l-1}^{\widehat{a}}+x_{l}^{\widehat{a}}}{2}<x_{l}^{\hat{a}}<$ $p^{*}\left(x_{l}^{\hat{a}}, \beta_{2}\right)$, it must be true that $U\left(\frac{x_{l-1}^{\widehat{a}}+x_{l}^{\widehat{a}}}{2}, x_{l}^{\hat{a}}, \beta_{2}\right)<U\left(x_{l}^{\hat{a}}, x_{l}^{\hat{a}}, \beta_{2}\right)$. Hence, we have $\Delta U\left(x_{l-1}^{\hat{a}}, x_{l}^{\hat{a}}, x_{l}^{\hat{a}}, \beta_{2}\right)>0$. Now examine how $\Delta U\left(x_{l-1}^{\hat{a}}, x_{l}^{\hat{a}}, x, \beta_{2}\right)$ changes when $x$ increases from $x_{l}^{\hat{a}}$ to $\bar{x}$. Since $U\left(\frac{x_{l}^{\widehat{a}}+x}{2}, x_{l}^{\hat{a}}, \beta_{2}\right)$ increases with $x$ when it is below $p^{*}\left(x_{l}^{\hat{a}}, \beta_{2}\right)$, and then decreases with $x$ when it is above $p^{*}\left(x_{l}^{\hat{a}}, \beta_{2}\right)$, we know that 
$\Delta U\left(x_{l-1}^{\hat{a}}, x_{l}^{\hat{a}}, x, \beta_{2}\right)$ changes in the same pattern with $x$. Hence, if there exists a $x_{l+1}^{\hat{a}} \in$ $\left(x_{l}^{\hat{a}}, \bar{x}\right]$ such that $\Delta U\left(x_{l-1}^{\hat{a}}, x_{l}^{\hat{a}}, x_{l+1}^{\hat{a}}, \beta_{2}\right)=0$, then $\Delta U\left(x_{l-1}^{\hat{a}}, x_{l}^{\hat{a}}, x, \beta_{2}\right)>0$ for all $x \in\left[x_{l}^{\hat{a}}, x_{l+1}^{\hat{a}}\right]$; otherwise, $\Delta U\left(x_{l-1}^{\hat{a}}, x_{l}^{\hat{a}}, x, \beta_{2}\right)>0$ for all $x \in\left[x_{l}^{\hat{a}}, \bar{x}\right]$. In the former case, since $\hat{a} \geq x_{1}\left(k, \beta_{2}\right)$, it must be true that $x_{l+1}^{\hat{a}} \geq x_{l+1}\left(k, \beta_{2}\right)$ by Lemma 4 . We have shown above that $x_{l+1}\left(k, \beta_{2}\right)>x_{l}^{\hat{a}}$. Hence, we have $x_{l}^{\hat{a}}<x_{l+1}\left(k, \beta_{2}\right) \leq x_{l+1}^{\hat{a}}$. In the latter case, it is clear that $x_{l}^{\hat{a}}<x_{l+1}\left(k, \beta_{2}\right) \leq \bar{x}$. It then follows that

$$
\Delta U\left(x_{l-1}^{\hat{a}}, x_{l}^{\hat{a}}, x_{l+1}\left(k, \beta_{2}\right), \beta_{2}\right)>0
$$

Now (24), (25), and (26) together imply that

$$
\Delta U\left(x_{l-1}^{\hat{a}}, x_{l}^{\hat{a}}, x_{l+1}\left(k, \beta_{1}\right), \beta_{1}\right)>0
$$

On the other hand, since $x_{l}^{\hat{a}}=x_{l}\left(k, \beta_{1}\right),\left\{\underline{x}, x_{1}^{\hat{a}}, \cdots, x_{l}^{\hat{a}}\right\} \quad$ and $\left\{\underline{x}, x_{1}\left(k, \beta_{1}\right), \cdots, x_{l}\left(k, \beta_{1}\right)\right\}$ are indeed two sequences described in the result with $n=l \leq k-1$. By the induction supposition, $x_{l-1}^{\hat{a}}>x_{l-1}\left(k, \beta_{1}\right)$. Since $U_{p}\left(p, x_{l}\left(k, \beta_{1}\right), \beta_{1}\right)>0$ for all $p<p^{*}\left(x_{l}\left(k, \beta_{1}\right), \beta_{1}\right)$, and $x_{l}\left(k, \beta_{1}\right)<p^{*}\left(x_{l}\left(k, \beta_{1}\right), \beta_{1}\right)$, we have $U_{p}\left(\frac{x+x_{l}\left(k, \beta_{1}\right)}{2}, x_{l}\left(k, \beta_{1}\right), \beta_{1}\right)>0$ for all $x<x_{l}\left(k, \beta_{1}\right)$, and hence $\Delta U_{1}\left(x, x_{l}\left(k, \beta_{1}\right), x_{l+1}\left(k, \beta_{1}\right), \beta_{1}\right)=-U_{p}\left(\frac{x+x_{l}\left(k, \beta_{1}\right)}{2}, x_{l}\left(k, \beta_{1}\right), \beta_{1}\right) \cdot \frac{1}{2}<0 \quad$ for $\quad$ all $x<x_{l}\left(k, \beta_{1}\right)$. Given that $x_{l-1}\left(k, \beta_{1}\right)<x_{l-1}^{\hat{a}}<x_{l}^{\hat{a}}=x_{l}\left(k, \beta_{1}\right)$, we have $\Delta U\left(x_{l-1}^{\hat{a}}, x_{l}^{\hat{a}}, x_{l+1}\left(k, \beta_{1}\right), \beta_{1}\right)<\Delta U\left(x_{l-1}\left(k, \beta_{1}\right), x_{l}\left(k, \beta_{1}\right), x_{l+1}\left(k, \beta_{1}\right), \beta_{1}\right)=0$

However, (27) and (28) contradict each other. Therefore, the result is true for $n=k$.

By induction, the result is true for any $n \geq 1$.

\section{Step 2.}

Next, I prove that $x_{1}\left(n, \beta_{1}\right)=x_{1}\left(n, \beta_{2}\right)$ implies that $x_{i}\left(n, \beta_{1}\right)>x_{i}\left(n, \beta_{2}\right)$ for all $i=2, \cdots, n$ by contradiction.

Suppose $x_{j}\left(n, \beta_{1}\right)=x_{j}\left(n, \beta_{2}\right)$ for some $j \geq 2$. Then the first $j+1$ elements of the two sequences form two sequences in Step 1 with $j+1$ elements. By the result proved in Step 1, we know that $x_{1}\left(n, \beta_{1}\right)<x_{1}\left(n, \beta_{2}\right)$, which contradicts the assumption. 
Now suppose that $x_{j}\left(n, \beta_{1}\right)<x_{j}\left(n, \beta_{2}\right)$ for some $j \geq 2$. Construct a sequence of solutions, $x^{b}=\left\{x_{0}^{b}, x_{1}^{b}, \cdots, x_{j}^{b}\right\}$, to the equation $U\left(\frac{x_{i-1}+x_{i}}{2}, x_{i}, \beta_{2}\right)=U\left(\frac{x_{i}+x_{i+1}}{2}, x_{i}, \beta_{2}\right)$ for $i=1, \cdots, j-1$, with $x_{0}^{b}=\underline{x}$ and $x_{1}^{b}=b$. Given $x_{j}\left(n, \beta_{1}\right)<x_{j}\left(n, \beta_{2}\right)$, and $x_{j}$ is an increasing function of $x_{1}$, there exists a $\hat{b}<x_{1}\left(n, \beta_{2}\right)$ such that $x_{j}^{\hat{b}}=x_{j}\left(n, \beta_{1}\right)$. Now denote $x\left(j, \beta_{1}\right)$ as the sequence consisting the first $j+1$ elements of $x\left(n, \beta_{1}\right)$. Compare the two sequences, $x^{\hat{b}}$ and $x\left(j, \beta_{1}\right)$. Then again, by the result proved in Step 1, we have $x_{1}^{\hat{b}}>x_{1}\left(j, \beta_{1}\right)$, i.e., $\hat{b}>x_{1}\left(n, \beta_{1}\right)$. However, $\hat{b}<x_{1}(n, \beta)$, then we have $x_{1}\left(n, \beta_{2}\right)>$ $x_{1}\left(n, \beta_{1}\right)$, which contradicts the assumption again.

Hence, it cannot be true that $x_{j}\left(n, \beta_{1}\right) \leq x_{j}\left(n, \beta_{2}\right)$ for some $j \geq 2$. Therefore, it must be true that $x_{i}\left(n, \beta_{1}\right)>x_{i}\left(n, \beta_{2}\right)$ for all $i=2, \cdots, n$.

\section{Step 3.}

Finally, I prove $N\left(\beta_{1}\right) \leq N\left(\beta_{2}\right)$ by contradiction.

Let $x\left(N\left(\beta_{1}\right), \beta_{1}\right)$ be the equilibrium partition of size $N\left(\beta_{1}\right)$, and $x\left(M, \beta_{2}\right)$ be a sequence of solutions to equation $U\left(\frac{x_{i-1}+x_{i}}{2}, x_{i}, \beta_{2}\right)=U\left(\frac{x_{i}+x_{i+1}}{2}, x_{i}, \beta_{2}\right)$ for $i=$ $1, \cdots, M-1$ with $x_{0}\left(M, \beta_{2}\right)=\underline{x}$, and $x_{1}\left(M, \beta_{2}\right)=x_{1}\left(N\left(\beta_{1}\right), \beta_{1}\right)$. Given the result proved in Step 2, we have $x_{i}\left(M, \beta_{2}\right)<x_{i}\left(N\left(\beta_{1}\right), \beta_{1}\right)$ for all $i=2, \cdots, N$. Hence it must be true that $M \geq N\left(\beta_{1}\right)$. It then follows that $N\left(\beta_{2}\right) \geq M \geq N\left(\beta_{1}\right)$.

Now consider the case when $\beta>\frac{2 \alpha}{\gamma}$. We need to prove that $N(\beta)$ is nonincreasing in $\beta$ in this case.

\section{Step 1'.}

Let $x\left(n, \beta_{1}\right)$ and $x\left(n, \beta_{2}\right)$ be a sequence of solutions to equation (9) for $\beta=\beta_{1}$ and $\beta=\beta_{2}$ respectively for $i=1,2, \cdots, n$, with $x_{0}\left(n, \beta_{1}\right)=x_{0}\left(n, \beta_{2}\right)=\bar{x}$, and $\beta_{1}<\beta_{2}$.

I first prove that if $x_{n}\left(n, \beta_{1}\right)=x_{n}\left(n, \beta_{2}\right) \geq \underline{x}$, then $x_{i}\left(n, \beta_{1}\right)<x_{i}\left(n, \beta_{2}\right)$ for all $i=1,2, \cdots, n-1$ by induction.

For $n=1$, the lemma is trivial.

For $n=2$, suppose $x_{2}\left(n, \beta_{1}\right)=x_{2}\left(n, \beta_{2}\right) \geq \underline{x}$, but $x_{1}\left(n, \beta_{1}\right) \geq x_{1}\left(n, \beta_{2}\right)$. 
$U\left(\frac{x_{1}\left(n, \beta_{1}\right)+\bar{x}}{2}, x_{1}\left(n, \beta_{1}\right), \beta_{2}\right)-U\left(\frac{x_{2}\left(n, \beta_{1}\right)+x_{1}\left(n, \beta_{1}\right)}{2}, x_{1}\left(n, \beta_{1}\right), \beta_{2}\right)-$

$\left[U\left(\frac{x_{1}\left(n, \beta_{1}\right)+\bar{x}}{2}, x_{1}\left(n, \beta_{1}\right), \beta_{1}\right)-U\left(\frac{x_{2}\left(n, \beta_{1}\right)+x_{1}\left(n, \beta_{1}\right)}{2}, x_{1}\left(n, \beta_{1}\right), \beta_{1}\right)\right]=$

$\int_{\beta_{1}}^{\beta_{2}} \frac{\int_{\frac{x_{2}\left(n, \beta_{1}\right)+x_{1}\left(n, \beta_{1}\right)}{2}}^{\frac{x_{1}\left(n, \beta_{1}\right)+\bar{x}}{2}}}{p \beta}\left(p, x_{1}\left(n, \beta_{1}\right), \beta\right) d p d \beta$

Since $p^{*}\left(x_{1}\left(n, \beta_{1}\right)\right)<\frac{x_{1}\left(n, \beta_{1}\right)+\bar{x}}{2}$, and $p^{*}\left(x_{1}\left(n, \beta_{1}\right)\right) \geq x_{1}\left(n, \beta_{1}\right)-\varepsilon+\frac{c}{\beta_{1}}$, we have $\frac{x_{1}\left(n, \beta_{1}\right)+\bar{x}}{2}>x_{1}\left(n, \beta_{1}\right)-\varepsilon+\frac{c}{\beta_{1}}>x_{1}\left(n, \beta_{1}\right)-\varepsilon+\frac{c}{\beta_{2}}$. Given that $U_{p \beta}(p, x, \beta) \leq 0$ for any $p$ and $U_{p \beta}(p, x, \beta)<0$ for $p \geq x-\varepsilon+\frac{c}{\beta}$, we have $U_{p \beta}\left(p, x_{1}\left(n, \beta_{1}\right), \beta\right)<0$ in a neighborhood of $\frac{x_{1}\left(n, \beta_{1}\right)+\bar{x}}{2}$ for any $\beta \in\left[\beta_{1}, \beta_{2}\right]$, hence

$\int_{\beta_{1}}^{\beta_{2}} \frac{\int_{x_{2}\left(n, \beta_{1}\right)+x_{1}\left(n, \beta_{1}\right)}^{\frac{x_{1}\left(n, \beta_{1}\right)+\bar{x}}{2}}}{2} U_{p \beta}\left(p, x_{1}\left(n, \beta_{1}\right), \beta\right) d p d \beta<0$.

Since $U\left(\frac{x_{1}\left(n, \beta_{1}\right)+\bar{x}}{2}, x_{1}\left(n, \beta_{1}\right), \beta_{1}\right)=U\left(\frac{x_{2}\left(n, \beta_{1}\right)+x_{1}\left(n, \beta_{1}\right)}{2}, x_{1}\left(n, \beta_{1}\right), \beta_{1}\right)$, we have

$U\left(\frac{x_{1}\left(n, \beta_{1}\right)+\bar{x}}{2}, x_{1}\left(n, \beta_{1}\right), \beta_{2}\right)-U\left(\frac{x_{2}\left(n, \beta_{1}\right)+x_{1}\left(n, \beta_{1}\right)}{2}, x_{1}\left(n, \beta_{1}\right), \beta_{2}\right)<0$.

On the other hand, let $\hat{x}_{2}$ be the solution to the equation $U\left(\frac{x_{2}+x_{1}\left(n, \beta_{1}\right)}{2}, x_{1}\left(n, \beta_{1}\right), \beta_{2}\right)=U\left(\frac{x_{1}\left(n, \beta_{1}\right)+\bar{x}}{2}, x_{1}\left(n, \beta_{1}\right), \beta_{2}\right)$. Then given that $x_{1}\left(n, \beta_{1}\right) \geq$ $x_{1}\left(n, \beta_{2}\right)$ and by Lemma 4 , we have $\hat{x}_{2} \geq x_{2}\left(n, \beta_{2}\right)$. Since $U(p, x, \beta)$ has a single peak, for any $p \leq \frac{\hat{x}_{2}+x_{1}\left(n, \beta_{1}\right)}{2}$, we have $U\left(p, x_{1}\left(n, \beta_{1}\right), \beta_{2}\right) \leq U\left(\frac{\hat{x}_{2}+x_{1}\left(n, \beta_{1}\right)}{2}, x_{1}\left(n, \beta_{1}\right), \beta_{2}\right)=$ $U\left(\frac{x_{1}\left(n, \beta_{1}\right)+\bar{x}}{2}, x_{1}\left(n, \beta_{1}\right), \beta_{2}\right)$. Given that $\hat{x}_{2} \geq x_{2}\left(n, \beta_{2}\right)=x_{2}\left(n, \beta_{1}\right)$, we know that $\frac{x_{2}\left(n, \beta_{1}\right)+x_{1}\left(n, \beta_{1}\right)}{2} \leq \frac{\hat{x}_{2}+x_{1}\left(n, \beta_{1}\right)}{2}$. Hence, we have

$U\left(\frac{x_{2}\left(n, \beta_{1}\right)+x_{1}\left(n, \beta_{1}\right)}{2}, x_{1}\left(n, \beta_{1}\right), \beta_{2}\right) \leq U\left(\frac{x_{1}\left(n, \beta_{1}\right)+\bar{x}}{2}, x_{1}\left(n, \beta_{1}\right), \beta_{2}\right)$

However, (29) and (30) contradict each other. Hence, the result is true when $n=2$.

Suppose the result is true for all $n=1,2, \cdots, k-1$. For $n=k$, suppose there exists some $1 \leq j \leq k-1$ such that $x_{j}\left(k, \beta_{1}\right) \geq x_{j}\left(k, \beta_{2}\right)$. Let $l$ be the largest index in those $j$ 's, then $x_{i}\left(k, \beta_{1}\right)<x_{i}\left(k, \beta_{2}\right)$ for all $l<i \leq k$. 
Define $\Delta U\left(x_{i-1}, x_{i}, x_{i+1}, \beta\right)=U\left(\frac{x_{i}+x_{i+1}}{2}, x_{i}, \beta\right)-U\left(\frac{x_{i-1}+x_{i}}{2}, x_{i}, \beta\right)$ for $\quad$ any $\underline{x} \leq x_{i+1}<x_{i}<x_{i-1} \leq \bar{x}$. Construct a sequence of solutions, $x^{a}=\left(x_{0}^{a}, x_{1}^{a}, \cdots, x_{l}^{a}\right)$, to the equation $\Delta U\left(x_{i-1}, x_{i}, x_{i+1}, \beta_{1}\right)=0$ for $i=1,2, \cdots, l-1$, with $x_{0}^{a}=\bar{x}$, and $x_{1}^{a}=a$. From the proof of Lemma 4, we know that $x_{l}^{a}$ is continuously increasing in $a$, so there must be a $\hat{a} \leq x_{1}\left(k, \beta_{1}\right)$ such that $x_{l}^{\hat{a}}=x_{l}\left(k, \beta_{2}\right) \leq x_{l}\left(k, \beta_{1}\right)$. Since $U_{p}\left(\frac{x+x_{l}\left(k, \beta_{2}\right)}{2}, x_{l}\left(k, \beta_{2}\right), \beta_{2}\right)>0$ for all $x \leq x_{l+1}\left(k, \beta_{2}\right)$, we have $\Delta U_{3}\left(x_{l-1}^{\hat{a}}, x_{l}^{\hat{a}}, x, \beta_{2}\right)=$ $U_{p}\left(\frac{x+x_{l}\left(k, \beta_{2}\right)}{2}, x_{l}\left(k, \beta_{2}\right), \beta_{2}\right) \cdot \frac{1}{2}>0$ for all $x \leq x_{l+1}\left(k, \beta_{2}\right)$.

Given that $x_{l+1}\left(k, \beta_{1}\right)<x_{l+1}\left(k, \beta_{2}\right)$, we have

$$
\Delta U\left(x_{l-1}^{\hat{a}}, x_{l}^{\hat{a}}, x_{l+1}\left(k, \beta_{1}\right), \beta_{2}\right)<\Delta U\left(x_{l-1}^{\hat{a}}, x_{l}^{\hat{a}}, x_{l+1}\left(k, \beta_{2}\right), \beta_{2}\right)
$$

Recall that $U_{p \beta}(p, x, \beta) \leq 0$ for any $p$ and $U_{p \beta}(p, x, \beta)<0$ for $p \geq x-\varepsilon+\frac{c}{\beta}$. Note that $x_{i}-\varepsilon+\frac{c}{\beta} \leq p^{*}\left(x_{i}\right)<\frac{x_{i}+x_{i-1}}{2}$; hence, $U_{\beta}(p, x, \beta)$ is strictly decreasing in $p$ in a neighborhood of $\frac{x_{i}+x_{i-1}}{2}$, and flat in $p$ elsewhere. For any $x_{i-1}>x_{i}>x_{i+1}$, we have $\frac{x_{i}+x_{i-1}}{2}>\frac{x_{i}+x_{i+1}}{2}$, hence

$$
\begin{aligned}
& \frac{d}{d \beta}\left\{\Delta U\left(x_{i-1}, x_{i}, x_{i+1}, \beta\right)\right\}=\frac{d}{d \beta}\left(U\left(\frac{x_{i}+x_{i+1}}{2}, x_{i}, \beta\right)-U\left(\frac{x_{i-1}+x_{i}}{2}, x_{i}, \beta\right)\right) \\
& =\frac{d}{d \beta}\left(U\left(\frac{x_{i}+x_{i+1}}{2}, x_{i}, \beta\right)\right)-\frac{d}{d \beta}\left(U\left(\frac{x_{i-1}+x_{i}}{2}, x_{i}, \beta\right)\right)>0 .
\end{aligned}
$$

Note that $x_{l}^{\hat{a}}=x_{l}\left(k, \beta_{2}\right)$, it must be true that $x_{l+1}\left(k, \beta_{2}\right)<x_{l}^{\hat{a}}$. Together with the fact that $x_{l+1}\left(k, \beta_{2}\right)>x_{l+1}\left(k, \beta_{1}\right)$, we must have $x_{l+1}\left(k, \beta_{1}\right)<x_{l}^{\hat{a}}<x_{l-1}^{\hat{a}}$. It then follows that

$$
\Delta U\left(x_{l-1}^{\hat{a}}, x_{l}^{\hat{a}}, x_{l+1}\left(k, \beta_{1}\right), \beta_{2}\right)>\Delta U\left(x_{l-1}^{\hat{a}}, x_{l}^{\hat{a}}, x_{l+1}\left(k, \beta_{1}\right), \beta_{1}\right)
$$

Define $p^{*}(x, \beta)=\operatorname{argmax}_{p}\{U(p, x, \beta)\}$. Note that when $\beta>\frac{2 \alpha}{\gamma}, p^{*}(x, \beta)<x$ for any $x$. Since $U_{p}\left(p, x_{l}^{\hat{a}}, \beta_{1}\right)<0$ for all $p>p^{*}\left(x_{l}^{\hat{a}}, \beta_{1}\right)$, and $\frac{x_{l-1}^{\widehat{a}}+x_{l}^{\widehat{a}}}{2}>x_{l}^{\hat{a}}>$ $p^{*}\left(x_{l}^{\hat{a}}, \beta_{1}\right)$, it must be true that $U\left(\frac{x_{l-1}^{\widehat{a}}+x_{l}^{\widehat{a}}}{2}, x_{l}^{\hat{a}}, \beta_{1}\right)<U\left(x_{l}^{\hat{a}}, x_{l}^{\hat{a}}, \beta_{1}\right)$. Hence, we have $\Delta U\left(x_{l-1}^{\hat{a}}, x_{l}^{\hat{a}}, x_{l}^{\hat{a}}, \beta_{1}\right)>0$. Now examine how $\Delta U\left(x_{l-1}^{\hat{a}}, x_{l}^{\hat{a}}, x, \beta_{1}\right)$ changes when $x$ decreases from $x_{l}^{\hat{a}}$ to $\underline{x}$. We know that $U\left(\frac{x_{l}^{\widehat{a}}+x}{2}, x_{l}^{\hat{a}}, \beta_{1}\right)$ increases with $x$ when it is below 
$p^{*}\left(x_{l}^{\hat{a}}, \beta_{1}\right)$, and then decreases with $x$ when it's above $p^{*}\left(x_{l}^{\hat{a}}, \beta_{1}\right)$, and we know that $\Delta U\left(x_{l-1}^{\hat{a}}, x_{l}^{\hat{a}}, x, \beta_{1}\right)$ changes in the same pattern with $x$. Hence, if there exists a $x_{l+1}^{\hat{a}} \in$ $\left[\underline{x}, x_{l}^{\hat{a}}\right)$ such that $\Delta U\left(x_{l-1}^{\hat{a}}, x_{l}^{\hat{a}}, x_{l+1}^{\hat{a}}, \beta_{1}\right)=0$, then $\Delta U\left(x_{l-1}^{\hat{a}}, x_{l}^{\hat{a}}, x, \beta_{1}\right)>0$ for all $x \in\left[x_{l+1}^{\hat{a}}, x_{l}^{\hat{a}}\right]$; otherwise, $\Delta U\left(x_{l-1}^{\hat{a}}, x_{l}^{\hat{a}}, x, \beta_{1}\right)>0$ for all $x \in\left[\underline{x}, x_{l}^{\hat{a}}\right]$. In the former case, since $\hat{a} \leq x_{1}\left(k, \beta_{1}\right)$, it must be true that $x_{l+1}^{\hat{a}} \leq x_{l+1}\left(k, \beta_{1}\right)$ by Lemma 4 . We have shown above that $x_{l+1}\left(k, \beta_{1}\right)<x_{l}^{\hat{a}}$. Hence, we have $x_{l}^{\hat{a}}>x_{l+1}\left(k, \beta_{1}\right) \geq x_{l+1}^{\hat{a}}$. In the latter case, it is clear that $x_{l}^{\hat{a}}>x_{l+1}\left(k, \beta_{1}\right) \geq \underline{x}$. It then follows that

$$
\Delta U\left(x_{l-1}^{\hat{a}}, x_{l}^{\hat{a}}, x_{l+1}\left(k, \beta_{1}\right), \beta_{1}\right)>0
$$

Now (31), (32), and (33) together imply that

$$
\Delta U\left(x_{l-1}^{\hat{a}}, x_{l}^{\hat{a}}, x_{l+1}\left(k, \beta_{2}\right), \beta_{2}\right)>0
$$

On the other hand, since $x_{l}^{\hat{a}}=x_{l}\left(k, \beta_{2}\right), \quad\left\{x_{l}^{\hat{a}}, \cdots, x_{1}^{\hat{a}}, \bar{x}\right\}$ and $\left\{x_{l}\left(k, \beta_{2}\right), \cdots, x_{1}\left(k, \beta_{2}\right), \bar{x}\right\}$ are indeed two sequences described in the result with $n=l \leq k-1$. By the induction supposition, we know that $x_{l-1}^{\hat{a}}<x_{l-1}\left(k, \beta_{2}\right)$. Since $U_{p}\left(p, x_{l}\left(k, \beta_{2}\right), \beta_{2}\right)<0$ for all $p>p^{*}\left(x_{l}\left(k, \beta_{2}\right), \beta_{2}\right)$, and $x_{l}\left(k, \beta_{2}\right)>p^{*}\left(x_{l}\left(k, \beta_{2}\right), \beta_{2}\right)$, we have $U_{p}\left(\frac{x+x_{l}\left(k, \beta_{2}\right)}{2}, x_{l}\left(k, \beta_{2}\right), \beta_{2}\right)<0$ for all $x>x_{l}\left(k, \beta_{2}\right)$, hence $\Delta U_{1}\left(x, x_{l}\left(k, \beta_{2}\right), x_{l+1}\left(k, \beta_{2}\right), \beta_{2}\right)=-U_{p}\left(\frac{x+x_{l}\left(k, \beta_{2}\right)}{2}, x_{l}\left(k, \beta_{2}\right), \beta_{2}\right) \cdot \frac{1}{2}>0 \quad$ for $\quad$ all $x>x_{l}\left(k, \beta_{2}\right)$. Given that $x_{l-1}\left(k, \beta_{2}\right)>x_{l-1}^{\hat{a}}>x_{l}^{\hat{a}}=x_{l}\left(k, \beta_{2}\right)$, we have $\Delta U\left(x_{l-1}^{\hat{a}}, x_{l}^{\hat{a}}, x_{l+1}\left(k, \beta_{2}\right), \beta_{2}\right)<\Delta U\left(x_{l-1}\left(k, \beta_{2}\right), x_{l}\left(k, \beta_{2}\right), x_{l+1}\left(k, \beta_{2}\right), \beta_{2}\right)=0$

However, (34) and (35) contradict each other. Therefore, the result is true for $n=k$.

\section{Step 2'.}

Next, I prove that $x_{1}\left(n, \beta_{1}\right)=x_{1}\left(n, \beta_{2}\right)$ implies that $x_{i}\left(n, \beta_{1}\right)>x_{i}\left(n, \beta_{2}\right)$ for all $i=2, \cdots, n$ by contradiction.

Suppose $x_{j}\left(n, \beta_{1}\right)=x_{j}\left(n, \beta_{2}\right)$ for some $j \geq 2$. Then the first $j+1$ elements of the two sequences form two sequences in Step 1' with $j+1$ elements. By the result proved in Step 1', we know that $x_{1}\left(n, \beta_{1}\right)<x_{1}\left(n, \beta_{2}\right)$, which contradicts the assumption. 
Now suppose that $x_{j}\left(n, \beta_{1}\right)<x_{j}\left(n, \beta_{2}\right)$ for some $j \geq 2$. Construct a sequence of solutions, $x^{b}=\left\{x_{0}^{b}, x_{1}^{b}, \cdots, x_{j}^{b}\right\}$, to the equation $U^{L}\left(\frac{x_{i-1}+x_{i}}{2}, x_{i}, \beta_{2}\right)=U^{L}\left(\frac{x_{i}+x_{i+1}}{2}, x_{i}, \beta_{2}\right)$ for $i=1, \cdots, j-1$, with $x_{0}^{b}=\bar{x}$ and $x_{1}^{b}=b$. Given $x_{j}\left(n, \beta_{1}\right)<x_{j}\left(n, \beta_{2}\right)$, and $x_{j}$ is an increasing function of $x_{1}$, there exists a $\hat{b}<x_{1}\left(n, \beta_{2}\right)$ such that $x_{j}^{\hat{b}}=x_{j}\left(n, \beta_{1}\right)$. Now denote $x\left(j, \beta_{1}\right)$ as the sequence consisting of the first $j+1$ elements of $x\left(n, \beta_{1}\right)$. Compare the two sequences, $x^{\hat{b}}$ and $x\left(j, \beta_{1}\right)$. Then by the result proved in Step 1', we know that $x_{1}^{\hat{b}}>x_{1}\left(j, \beta_{1}\right)$, i.e., $\hat{b}>x_{1}\left(n, \beta_{1}\right)$. However, $\hat{b}<x_{1}\left(n, \beta_{2}\right)$, then we have $x_{1}\left(n, \beta_{2}\right)>x_{1}\left(n, \beta_{1}\right)$, which contradicts the assumption again.

Hence, it cannot be true that $x_{j}\left(n, \beta_{1}\right) \leq x_{j}\left(n, \beta_{2}\right)$ for some $j \geq 2$. Therefore, it must be true that $x_{i}\left(n, \beta_{1}\right)>x_{i}\left(n, \beta_{2}\right)$ for all $i=2, \cdots, n$.

Step 3'.

Finally, I prove $N\left(\beta_{1}\right) \geq N\left(\beta_{2}\right)$ by contradiction.

Let $x\left(N\left(\beta_{2}\right), \beta_{2}\right)$ be the equilibrium partition of size $N\left(\beta_{2}\right)$, and $x\left(M, \beta_{1}\right)$ be a sequence of solutions to equation $U^{L}\left(\frac{x_{i-1}+x_{i}}{2}, x_{i}, \beta_{1}\right)=U^{L}\left(\frac{x_{i}+x_{i+1}}{2}, x_{i}, \beta_{1}\right)$ for $i=$ $1, \cdots, M-1$ with $x_{0}\left(M, \beta_{1}\right)=\bar{x}$, and $x_{1}\left(M, \beta_{1}\right)=x_{1}\left(N\left(\beta_{2}\right), \beta_{2}\right)$. Given the result proved in Step 2, we have $x_{i}\left(M, \beta_{1}\right)>x_{i}\left(N\left(\beta_{2}\right), \beta_{2}\right)$ for all $i=2, \cdots, N$. Hence it must be true that $M \geq N\left(\beta_{2}\right)$. It then follows that $N\left(\beta_{1}\right) \geq M \geq N\left(\beta_{2}\right)$.

When $\beta=\frac{2 \alpha}{\gamma}, p^{*}(x)=x$, the equilibrium in which the maximum amount of information is communicated is a fully revealing equilibrium, where the manager discloses her information precisely and the stock price is equal to the fundamentals of the firm. In this case, the size of the equilibrium partition is infinite.

In summary, when $\beta \leq \frac{2 \alpha}{\gamma}$, the size of the equilibrium partition is weakly increasing towards infinity as $\beta$ increases towards $\frac{2 \alpha}{\gamma}$; when $\beta \geq \frac{2 \alpha}{\gamma}$, the size of the equilibrium partition is weakly decreasing in $\beta$.

Q.E.D.

\section{Proof for Corollary:}


(by contradiction) Suppose there is an equilibrium with a two-interval partition. Then by Proposition 2, there must be one type $x \in[\underline{x}, \bar{x}]$, such that $U\left(\frac{x+x}{2}, x\right)=U\left(\frac{x+\bar{x}}{2}, x\right)$.

When $\beta \leq \frac{2 \alpha}{\gamma\left(\frac{\bar{x}-\underline{x}}{\varepsilon}+1\right)}$, we have $p^{*}(x)=x+\left(\frac{2 \alpha}{\gamma \beta}-1\right) \varepsilon \geq \bar{x}$ for any $x \in[\underline{x}, \bar{x}]$. Since $\frac{x+x}{2}<\frac{x+\bar{x}}{2} \leq \bar{x}$, we have $\frac{x+x}{2}<\frac{x+\bar{x}}{2} \leq p^{*}(x)$. Hence we have $U\left(\frac{x+x}{2}, x\right)<$ $U\left(\frac{x+\bar{x}}{2}, x\right)$ for any type $x \in[\underline{x}, \bar{x}]$. Therefore, there cannot exist any equilibrium with a two-interval partition.

When $\beta \geq \frac{2 \alpha}{\gamma\left(1-\frac{\bar{x}-\underline{x}}{\varepsilon}\right)}$, we have $p^{*}(x)=x+\left(\frac{2 \alpha}{\gamma \beta}-1\right) \varepsilon \leq \underline{x}$ for any $x \in[\underline{x}, \bar{x}]$. Since $\underline{x} \leq \frac{\underline{x}+x}{2}<\frac{x+\bar{x}}{2}$, we have $p^{*}(x) \leq \frac{\underline{x}+x}{2}<\frac{x+\bar{x}}{2}$. Hence, we have $U\left(\frac{x+x}{2}, x\right)<$ $U\left(\frac{x+\bar{x}}{2}, x\right)$ for any type $x \in[\underline{x}, \bar{x}]$. Therefore, there cannot exist any equilibrium with a two-interval partition.

By Proposition 3, we know that if there does not exist an equilibrium with a twointerval partition, there cannot exist any equilibrium with more than two intervals in the equilibrium partition. Therefore, there does not exist any informative equilibrium when $\beta \leq \frac{2 \alpha}{\gamma\left(\frac{\bar{x}-\underline{x}}{\varepsilon}+1\right)}$ or $\beta \geq \frac{2 \alpha}{\gamma\left(1-\frac{\bar{x}-\underline{x}}{\varepsilon}\right)}$.

Q.E.D.

\section{Proof of Proposition 5:}

Recall that there are three cases of the locus of $\frac{x_{i-1}+x_{i}}{2}$ and $\frac{x_{i}+x_{i+1}}{2}$ on the three pieces of the utility function of type $x_{i}$. If $\frac{x_{i-1}+x_{i}}{2}<\underline{p}\left(x_{i}\right)$, it must be true that $\frac{x_{i}+x_{i+1}}{2}>\hat{p}$; and if $\underline{p}\left(x_{i}\right)<\frac{x_{i-1}+x_{i}}{2}<p^{*}\left(x_{i}\right)$, it must be true that $p^{*}\left(x_{i}\right)<\frac{x_{i}+x_{i+1}}{2}<\hat{p}$, where $\hat{p}=x_{i}+$ $\left(\frac{4 \alpha}{\gamma \beta}-1\right) \varepsilon-\frac{c}{\beta} \in\left(p^{*}\left(x_{i}\right), \bar{p}\left(x_{i}\right)\right)$. Hence, the proof is done again in the three cases below.

Case (1): $\frac{x_{i-1}+x_{i}}{2}<\underline{p}\left(x_{i}\right)$, and $\hat{p}<\frac{x_{i}+x_{i+1}}{2}<\bar{p}\left(x_{i}\right)$.

Given that $U\left(\frac{x_{i-1}+x_{i}}{2}, x_{i}\right)=U\left(\frac{x_{i}+x_{i+1}}{2}, x_{i}\right)$, and that $U\left(\underline{p}\left(x_{i}\right), x_{i}\right)=U\left(\hat{p}, x_{i}\right)$, we have 


$$
\int_{\frac{x_{-1}+x_{i}}{2}}^{\frac{p}{2}\left(x_{i}\right)} U_{p}\left(p, x_{i}\right) d p=\int_{\frac{x_{i}+x_{i+1}}{2}}^{\hat{p}} U_{p}\left(p, x_{i}\right) d p .
$$

Since $U_{p}\left(\hat{p}, x_{i}\right)=\alpha-\frac{\gamma \beta}{2 \varepsilon}\left(\frac{4 \alpha}{\gamma \beta} \varepsilon-\frac{c}{\beta}\right)=-\alpha+\frac{\gamma c}{2 \varepsilon}>-\alpha, \quad U_{p}\left(\bar{p}\left(x_{i}\right), x_{i}\right)=-\alpha-$ $\frac{\gamma c}{2 \varepsilon}<-\alpha$, and $U_{p}\left(p, x_{i}\right)$ is continuously decreasing in $p$ on $\left[\hat{p}, \bar{p}\left(x_{i}\right)\right)$, there exists a $\tilde{p} \in\left[\hat{p}, \bar{p}\left(x_{i}\right)\right)$ such that $U_{p}\left(\tilde{p}, x_{i}\right)=-\alpha$, and $U_{p}\left(p, x_{i}\right)>-\alpha$ when $p<\tilde{p}$ and $U_{p}\left(p, x_{i}\right)<-\alpha$ when $p>\tilde{p}$. Since $U_{p}\left(p, x_{i}\right) \equiv \alpha$ when $p<\underline{p}\left(x_{i}\right)$, by equation (36), we know that if $\frac{x_{i}+x_{i+1}}{2}<\tilde{p}, \frac{x_{i}+x_{i+1}}{2}-\hat{p}-\left(\underline{p}\left(x_{i}\right)-\frac{x_{i-1}+x_{i}}{2}\right)>0$ and it increases with $\frac{x_{i}+x_{i+1}}{2}$. If $\frac{x_{i}+x_{i+1}}{2} \in\left[\tilde{p}, \bar{p}\left(x_{i}\right)\right]$, then $\frac{x_{i}+x_{i+1}}{2}-\hat{p}-\left(\underline{p}\left(x_{i}\right)-\frac{x_{i-1}+x_{i}}{2}\right)$ decreases with $\frac{x_{i}+x_{i+1}}{2}$ and is minimized when $\frac{x_{i}+x_{i+1}}{2}=\bar{p}\left(x_{i}\right)$. But $\frac{x_{i}+x_{i+1}}{2}-\hat{p}-\left(\underline{p}\left(x_{i}\right)-\frac{x_{i-1}+x_{i}}{2}\right)=\frac{x_{i}+x_{i+1}}{2}-$ $\left(x_{i}+\left(\frac{4 \alpha}{\gamma \beta}-1\right) \varepsilon-\frac{c}{\beta}\right)-\left(x_{i}-\varepsilon+\frac{c}{\beta}-\frac{x_{i-1}+x_{i}}{2}\right)=\frac{l_{i+1}}{2}-\frac{l_{i}}{2}-\left(\frac{4 \alpha}{\gamma \beta}-2\right) \varepsilon$, hence $\frac{l_{i+1}}{2}-\frac{l_{i}}{2}$ is minimal when $\frac{x_{i}+x_{i+1}}{2}=\bar{p}\left(x_{i}\right)$, and maximal when $\frac{x_{i}+x_{i+1}}{2}=\tilde{p}$. Thus, we only need to prove that if $\beta<\frac{2 \alpha}{\gamma}, \frac{l_{i+1}}{2}-\frac{l_{i}}{2}>0$ when $\frac{x_{i}+x_{i+1}}{2}=\bar{p}\left(x_{i}\right)$, and if $\beta>\frac{2 \alpha+\frac{\left(\frac{\gamma c}{2 \varepsilon}\right)^{2}}{2 \alpha}}{\gamma}, \frac{l_{i+1}}{2}-\frac{l_{i}}{2}<0$ when $\frac{x_{i}+x_{i+1}}{2}=\tilde{p}$.

First, consider the case where $\beta<\frac{2 \alpha}{\gamma}$.

To prove that $\frac{l_{i+1}}{2}-\frac{l_{i}}{2}>0$ when $\frac{x_{i}+x_{i+1}}{2}=\bar{p}\left(x_{i}\right)$, first, solve for $\frac{x_{i-1}+x_{i}}{2}$ when $\frac{x_{i}+x_{i+1}}{2}=\bar{p}\left(x_{i}\right)$. Recall that $U(p, x)=\alpha p-\frac{\gamma \beta}{4 \varepsilon}\left[(p-x+\varepsilon)^{2}-\left(\frac{c}{\beta}\right)^{2}\right]$ when $p \in$ $[\underline{p}(x), \bar{p}(x)] ;$ hence, when $\frac{x_{i}+x_{i+1}}{2}=\bar{p}\left(x_{i}\right), U\left(\frac{x_{i}+x_{i+1}}{2}, x_{i}\right)=\alpha \cdot \bar{p}\left(x_{i}\right)-\frac{\gamma \beta}{4 \varepsilon}\left[\left(\bar{p}\left(x_{i}\right)-\right.\right.$ $\left.\left.x_{i}+\varepsilon\right)^{2}-\left(\frac{c}{\beta}\right)^{2}\right]=\alpha \cdot\left(x_{i}+\varepsilon+\frac{c}{\beta}\right)-\frac{\gamma \beta}{4 \varepsilon}\left[\left(x_{i}+\varepsilon+\frac{c}{\beta}-x_{i}+\varepsilon\right)^{2}-\left(\frac{c}{\beta}\right)^{2}\right]=\alpha$. $\left(x_{i}+\varepsilon+\frac{c}{\beta}\right)-\frac{\gamma \beta}{4 \varepsilon}\left(4 \varepsilon^{2}+4 \varepsilon \cdot \frac{c}{\beta}\right)=\alpha \cdot\left(x_{i}+\varepsilon+\frac{c}{\beta}\right)-\gamma \beta \varepsilon-\gamma c$. Since $U(p, x)=\alpha p$ when $p<\underline{p}(x)$, we have $U\left(\frac{x_{i-1}+x_{i}}{2}, x_{i}\right)=\alpha \cdot \frac{x_{i-1}+x_{i}}{2}$. Given that $U\left(\frac{x_{i-1}+x_{i}}{2}, x_{i}\right)=$ $U\left(\frac{x_{i}+x_{i+1}}{2}, x_{i}\right)$, we have $\alpha \cdot \frac{x_{i-1}+x_{i}}{2}=\alpha \cdot\left(x_{i}+\varepsilon+\frac{c}{\beta}\right)-\gamma \beta \varepsilon-\gamma c$; hence, $\frac{x_{i-1}+x_{i}}{2}=x_{i}+$ $\varepsilon+\frac{c}{\beta}-\frac{\gamma \beta \varepsilon+\gamma c}{\alpha}$; thus, $\frac{l_{i}}{2}=\frac{\gamma \beta \varepsilon+\gamma c}{\alpha}-\left(\varepsilon+\frac{c}{\beta}\right)=\left(\frac{\gamma \beta}{\alpha}-1\right) \varepsilon+\left(\frac{\gamma \beta}{\alpha}-1\right) \frac{c}{\beta}=\left(\frac{\gamma \beta}{\alpha}-1\right)(\varepsilon+$ 
$\left.\frac{c}{\beta}\right)$. Since $\frac{x_{i}+x_{i+1}}{2}=\bar{p}\left(x_{i}\right)=x_{i}+\varepsilon+\frac{c}{\beta}, \frac{l_{i+1}}{2}=\varepsilon+\frac{c}{\beta}$. Hence, $\frac{l_{i+1}}{2}-\frac{l_{i}}{2}=\left(2-\frac{\gamma \beta}{\alpha}\right)\left(\varepsilon+\frac{c}{\beta}\right)$.

Given that $\beta<\frac{2 \alpha}{\gamma}$, we know that $\frac{\gamma \beta}{\alpha}<2$; hence, $\frac{l_{i+1}}{2}-\frac{l_{i}}{2}>0$.

Now consider the case where $\beta>\frac{2 \alpha+\frac{\left(\frac{\gamma c}{2 \varepsilon}\right)^{2}}{2 \alpha}}{\gamma}$.

To prove that $\frac{l_{i+1}}{2}-\frac{l_{i}}{2}<0$ when $\frac{x_{i}+x_{i+1}}{2}=\tilde{p}$, first, solve for $\frac{x_{i-1}+x_{i}}{2}$ when $\frac{x_{i}+x_{i+1}}{2}=$ $\tilde{p}$. Since $U_{p}\left(\tilde{p}, x_{i}\right)=\alpha-\frac{\gamma \beta}{2 \varepsilon}\left(\tilde{p}-x_{i}+\varepsilon\right)=-\alpha$, we have $\tilde{p}=x_{i}+\left(\frac{4 \alpha}{\gamma \beta}-1\right) \varepsilon$. When $\frac{x_{i}+x_{i+1}}{2}=\tilde{p} \quad, \quad U\left(\frac{x_{i}+x_{i+1}}{2}, x_{i}\right)=\alpha \cdot \tilde{p}-\frac{\gamma \beta}{4 \varepsilon}\left[\left(\tilde{p}-x_{i}+\varepsilon\right)^{2}-\left(\frac{c}{\beta}\right)^{2}\right]=\alpha \cdot\left(x_{i}+\right.$ $\left.\left(\frac{4 \alpha}{\gamma \beta}-1\right) \varepsilon\right)-\frac{\gamma \beta}{4 \varepsilon}\left[\left(x_{i}+\left(\frac{4 \alpha}{\gamma \beta}-1\right) \varepsilon-x_{i}+\varepsilon\right)^{2}-\left(\frac{c}{\beta}\right)^{2}\right]=\alpha \cdot\left(x_{i}+\left(\frac{4 \alpha}{\gamma \beta}-1\right) \varepsilon\right)-\frac{\gamma \beta}{4 \varepsilon}$. $\left[\left(\frac{4 \alpha}{\gamma \beta} \cdot \varepsilon\right)^{2}-\left(\frac{c}{\beta}\right)^{2}\right]=\alpha \cdot\left(x_{i}-\varepsilon\right)+\frac{\gamma \beta}{4 \varepsilon}\left(\frac{c}{\beta}\right)^{2}$. Since $U(p, x)=\alpha p$ when $p<\underline{p}(x)$, we have $U\left(\frac{x_{i-1}+x_{i}}{2}, x_{i}\right)=\alpha \cdot \frac{x_{i-1}+x_{i}}{2}$. Given that $U\left(\frac{x_{i-1}+x_{i}}{2}, x_{i}\right)=U\left(\frac{x_{i}+x_{i+1}}{2}, x_{i}\right)$, we have $\alpha \cdot \frac{x_{i-1}+x_{i}}{2}=\alpha \cdot\left(x_{i}-\varepsilon\right)+\frac{\gamma \beta}{4 \varepsilon}\left(\frac{c}{\beta}\right)^{2}$; hence, $\frac{x_{i-1}+x_{i}}{2}=x_{i}-\varepsilon+\frac{\gamma \beta}{4 \alpha \varepsilon}\left(\frac{c}{\beta}\right)^{2} ;$ thus, $\frac{l_{i}}{2}=\varepsilon-$ $\frac{\gamma \beta}{4 \alpha \varepsilon}\left(\frac{c}{\beta}\right)^{2}$. Since $\frac{x_{i}+x_{i+1}}{2}=\tilde{p}=x_{i}+\left(\frac{4 \alpha}{\gamma \beta}-1\right) \varepsilon, \frac{l_{i+1}}{2}=\left(\frac{4 \alpha}{\gamma \beta}-1\right) \varepsilon$. Hence, $\frac{l_{i+1}}{2}-\frac{l_{i}}{2}=$ $\left(\frac{4 \alpha}{\gamma \beta}-1\right) \varepsilon-\left[\varepsilon-\frac{\gamma \beta}{4 \alpha \varepsilon}\left(\frac{c}{\beta}\right)^{2}\right]=\left(\frac{4 \alpha}{\gamma \beta}+\frac{\gamma \beta}{4 \alpha}\left(\frac{c}{\beta \varepsilon}\right)^{2}-2\right) \varepsilon$. Given that $\beta>\frac{2 \alpha+\frac{\left(\frac{\gamma c}{2 \varepsilon}\right)^{2}}{2 \alpha}}{\gamma}$, we know that $(\gamma \beta-2 \alpha) \cdot 2 \alpha>\left(\frac{\gamma c}{2 \varepsilon}\right)^{2}$; hence, $\left(\frac{c}{\varepsilon}\right)^{2}<\frac{(2 \gamma \beta-4 \alpha) \cdot 4 \alpha}{\gamma^{2}}$; thus, $\left(\frac{c}{\beta \varepsilon}\right)^{2}<\frac{(2 \gamma \beta-4 \alpha)}{\gamma \beta} \cdot \frac{4 \alpha}{\gamma \beta}$; therefore, $\frac{\gamma \beta}{4 \alpha}\left(\frac{c}{\beta \varepsilon}\right)^{2}+\frac{4 \alpha}{\gamma \beta}<2$, i.e., $\frac{l_{i+1}}{2}-\frac{l_{i}}{2}<0$.

Case (2): $\frac{x_{i-1}+x_{i}}{2}<\underline{p}\left(x_{i}\right)$, and $\frac{x_{i}+x_{i+1}}{2}>\bar{p}\left(x_{i}\right)$.

In this case, $U\left(\frac{x_{i-1}+x_{i}}{2}, x_{i}\right)=U\left(\frac{x_{i}+x_{i+1}}{2}, x_{i}\right)$ implies that $\alpha \cdot \frac{x_{i-1}+x_{i}}{2}=\alpha \cdot \frac{x_{i}+x_{i+1}}{2}-\gamma \beta\left(\frac{x_{i}+x_{i+1}}{2}-x_{i}\right), i \geq 1$

Reorganize the equation, we have

$$
\begin{aligned}
& \gamma \beta\left(x_{i+1}-x_{i}\right)=\alpha\left(x_{i+1}-x_{i-1}\right) \\
& \gamma \beta l_{i+1}=\alpha\left(l_{i+1}+l_{i}\right) \\
& \frac{l_{i+1}}{l_{i+1}+l_{i}}=\frac{\alpha}{\gamma \beta}
\end{aligned}
$$


When $\beta<\frac{2 \alpha}{\gamma}$, we have $\frac{\alpha}{\gamma \beta}>\frac{1}{2}$; hence, $l_{i}<l_{i+1}$; when $\beta>\frac{2 \alpha+\frac{\left(\frac{\gamma c}{2 \varepsilon}\right)^{2}}{2 \alpha}}{\gamma}>\frac{2 \alpha}{\gamma}$, we have $\frac{\alpha}{\gamma \beta}<\frac{1}{2}$; hence, $l_{i}>l_{i+1}$.

Case (3): $\underline{p}\left(x_{i}\right)<\frac{x_{i-1}+x_{i}}{2}<p^{*}\left(x_{i}\right)$, and $p^{*}\left(x_{i}\right)<\frac{x_{i}+x_{i+1}}{2}<\hat{p}$.

$$
U\left(\frac{x_{i-1}+x_{i}}{2}, x_{i}\right)=U\left(\frac{x_{i}+x_{i+1}}{2}, x_{i}\right) \text { implies that } p^{*}\left(x_{i}\right)-\frac{x_{i-1}+x_{i}}{2}=\frac{x_{i}+x_{i+1}}{2}-p^{*}\left(x_{i}\right)
$$
i.e., $x_{i}+\left(\frac{2 \alpha}{\gamma \beta}-1\right) \varepsilon-\frac{x_{i-1}+x_{i}}{2}=\frac{x_{i}+x_{i+1}}{2}-\left[x_{i}+\left(\frac{2 \alpha}{\gamma \beta}-1\right) \varepsilon\right]$. Reorganize the equation, we have $\frac{l_{i}}{2}=\frac{l_{i+1}}{2}-2\left(\frac{2 \alpha}{\gamma \beta}-1\right) \varepsilon$.

When $\beta<\frac{2 \alpha}{\gamma}$, we have $\frac{2 \alpha}{\gamma \beta}-1>0$; hence, $l_{i}<l_{i+1}$; when $\beta>\frac{2 \alpha+\frac{\left(\frac{\gamma c}{2 \varepsilon}\right)^{2}}{2 \alpha}}{\gamma}>\frac{2 \alpha}{\gamma}$, we have $\frac{2 \alpha}{\gamma \beta}-1<0$; hence, $l_{i}>l_{i+1}$.

Q.E.D. 